\title{
Einlässe strahlgetriebener Flugzeuge
}

Um fliegen zu können, müssen Flugzeuge die auf sie wirkende Schwerkraft und Widerstandskraft überwinden. Dafür benötigen sie eine Auftriebskraft, die größer ist als die Schwerkraft, und eine Schubkraft, die den Roll- und Luftwiderstand übersteigt. Während der Auftrieb durch die Umströmung der Tragflächen des Flugzeugs erzeugt wird, wird der Schub in der modernen Luftfahrt überwiegend durch Zweistrom-Strahltriebwerke erzeugt.

Damit diese Triebwerke Schub erzeugen können, benötigen sie eine stetige Luftzufuhr, die das Triebwerk durchströmt. Der zugeführte Luftmassenstrom wird innerhalb des Triebwerks zuerst vom Fan, einem ummantelten Propeller, angesaugt und verdichtet. Anschließend wird verdichtete Luft in einen Kernmassenstrom und einen Nebenmassenstrom aufgeteilt. Die Luft des Kernmassenstroms wird im verbleibenden Verdichtersystem weiter komprimiert. Im Anschluss daran wird sie mit Kerosin vermischt und in der Brennkammer verbrannt. Die dadurch freigesetzte Energie wird zu einem großen Teil in der Turbine genutzt, um das Verdichtersystem anzutreiben. Abschließend wird die Luft des Kernmassenstroms gemeinsam mit dem Nebenmassenstrom in Form eines Austrittsstrahls über die Düse aus dem Triebwerk ausgeleitet. Durch die Druckund Geschwindigkeitsdifferenz des Austrittsstrahls im Vergleich zur Umgebungsluft wird der Triebwerksschub erzeugt. Der Hauptanteil des Schubs moderner Zweistrom-Strahltriebwerke wird hierbei durch den Nebenmassenstrom erzeugt.

Die Sicherstellung der angesprochenen Luftzufuhr in allen Betriebszuständen ist die Hauptaufgabe des Triebwerkseinlasses. Der Einlass ist der vor dem Fan befindliche Bestandteil der Gondel, welche das Triebwerk ummantelt, vgl. Abbildung 1.1. Bei der Luftzufuhr sind die vom Triebwerk geforderten Werte des Luftmassenstroms, sowie die Geschwindigkeit und die Gleichförmigkeit der Fananströmung vom Einlass umzusetzen. Andernfalls können auf den Fan und 
das restliche Verdichtersystem erhöhte Belastungen wirken und Strömungsablösungen bis hin zum Verdichterpumpen auftreten. Dies kann neben mechanischen Beschädigungen des Triebwerks vor allem Schubverlust zur Folge haben, was beispielsweise während des Flugzeugstarts zu gefährlichen Ereignissen führen kann und folglich zu vermeiden ist.

Für das Verständnis der Inhalte dieser Arbeit wird kein tiefergehendes Wissen über die Funktionsweise von Flugzeugtriebwerken vorausgesetzt. Bei Bedarf wird jedoch auf die zahlreich vorhandenen Fachbücher [8], [10], [47], [60], [61], [62], [63], [64], [65], [66], [67], [68], [69], [70], [71], [72], [73], [74], [75] verwiesen. Von den deutschsprachigen Autoren sind insbesondere Bräunling [10] und Rick [8] aufgrund des Umfangs und der Aktualität ihrer Werke hervorzuheben. Darüber hinaus geben Linke-Diesinger [76], Rossow et al. [77] und Moir et al. [78], [79], [80] einen Überblick über die Systeme der Triebwerksgondel.

Der Großteil der oben genannten Bücher enthält auch grundlegende Informationen über die Aufgaben, die Funktionsweise und die Gestaltung des Triebwerkseinlasses. Tiefergehende Informationen, insbesondere über die Aerodynamik von Einlässen, stellen Seddon und Goldsmith [11] bereit. Zudem behandelt eine Vielzahl wissenschaftlicher Abhandlungen die Einlassgeometrie, u. a. [12], [13], [14], [15], [16], [17], [18], [19], [20]. Die konstruktive Gestaltung von Triebwerkseinlässen fasst Sóbester [9], [46] zusammen.

\subsection{Einlassarten}

Basierend auf der angestrebten Fluggeschwindigkeit, dem Zweck ihrer Anwendung und der Epoche ihrer Entwicklung verwenden strahlgetriebene Flugzeuge verschiedene Einlassbauarten. Die angestrebte Fluggeschwindigkeit bestimmt die Anström-Machzahl des Einlasses. Dabei ist zu beachten, dass die geforderte Anström-Machzahl des auf den Einlass folgenden Fans höchstens Mach 0,6 betragen sollte [7], [10, S. 944]. Folglich ist bei höheren Fluggeschwindigkeiten innerhalb des Einlasses eine Verzögerung des Luftstroms erforderlich. Diese Umwandlung von kinetischer Energie in Druckenergie wird durch die Einlassgeometrie bestimmt. Hierbei hat die Anström-Machzahl des Einlasses einen erheblichen Einfluss auf die erreichbare Effizienz des Einlasses [8, S. 285]. 


\subsubsection{Starre subsonische Pitot-Einlässe}

Für Unterschallflüge werden fast ausschließlich annähernd ringförmige PitotEinlässe verwendet. Der Name Pitot-Einlass rührt von der Ähnlichkeit zu PitotRohren, die für die Messung der Strömungsgeschwindigkeit verwendet werden, her [7]. Pitot-Einlässe sind verhältnismäßig kurz und verzichten zumeist auf Stellmechanismen. Sie weisen eine runde Einlasslippe und einen diffusorförmigen Strömungskanal auf.

Die detaillierte Gestalt des Pitot-Einlasses hängt auch von der Art der Triebwerksmontage ab. Diese hat zudem einen großen Einfluss auf die Anströmung des Einlasses. Strahltriebwerke heutiger Unterschallflugzeuge sind am Rumpf oder an den Tragflügeln montiert. Die Flügelmontage kann Herausforderungen mit dem Mindestbodenabstand sowie Strömungs- und Lärminteraktionen mit den Tragflächen nach sich ziehen [81, S. 82]. Diese Art der Triebwerksmontage wird vorrangig bei Verkehrsflugzeugen verwendet. Bei der Rumpfmontage müssen potenzielle Störungen der Triebwerksanströmung, der zusätzliche Lasteintrag in den Flugzeugrumpf und die Verlegung erforderlicher Leitungen zu den Tragflächen durch die Kabine beachtet werden. [81, S. 82]. Die Triebwerke von Geschäftsflugzeugen sind häufig an den Seiten des Rumpfes angebracht, vgl. Abbildung 2.1. Weitere Einflüsse auf die Gestaltung von Pitot-Einlässen werden in Abschnitt 2.2 erläutert.

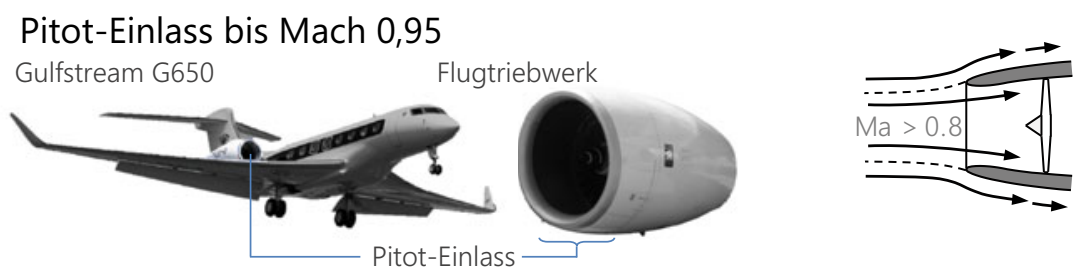

Abbildung 2.1 Anwendungen von Pitot-Einlässen im Unterschallbereich [A2]

\subsubsection{Starre supersonische Pitot-Einlässe bis Mach 1,6}

Bei Überschallflügen liegt die Anström-Machzahl des Einlasses über Mach 1 und muss folglich zum Fan hin reduziert werden. Dies wird durch einen oder mehrere Verdichtungsstöße erreicht. Für maximale Fluggeschwindigkeiten bis Mach 1,6 
werden aufgrund der verhältnismäßig geringen Masse und Komplexität vorrangig Pitot-Einlässe verwendet [8, S. 284], [46]. Bei dieser Bauart bildet sich vor dem Einlass ein senkrechter Verdichtungsstoß aus, der die Strömung direkt in den Unterschallbereich überführt, vgl. Abbildung 2.2.

\section{Geradstoß-Pitot-Einlass bis Mach 1,6}

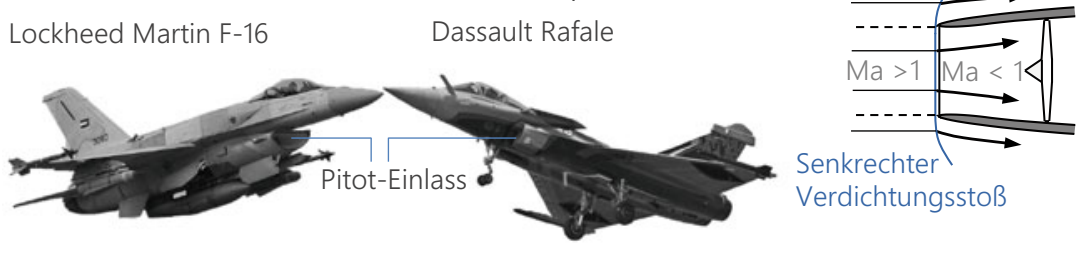

Abbildung 2.2 Anwendungen von Pitot-Einlässen im Überschallbereich [A3]

Pitot-Einlässe für den Überschallbetrieb nutzen eine scharfkantige Einlasslippe, sind länger als Pitot-Einlässe für den reinen Unterschallbetrieb und verzichten zumeist ebenso auf komplexe Stellmechanismen [8, S. 284]. Beispiele für Überschall-Pitot-Einlässe sind vorrangig bei Militäranwendungen der 50er und 60er Jahre anzutreffen [9]. Um den Widerstand zu minimieren, sind diese Einlässe häufig sehr nah am Flugzeugrumpf montiert, zwischen Rumpf und Flügel oder in den Rumpf integriert. So sind die Einlässe der Vought F-8 Crusader und der Lockheed Martin F-16 unterhalb des Rumpfes angebracht [9]. In die Nase des Rumpfes integriert, sind die Einlässe der MiG-15, der Gloster E28/39 oder der F-86 A Sabre, die trotz entsprechender Zielstellung teilweise keine Überschallgeschwindigkeiten erreicht haben [9].

\subsubsection{Variable supersonische Einlässe}

Mit steigender Machzahl vor dem senkrechten Verdichtungsstoß nehmen auch die Verluste dieses Verdichtungsstoßes zu. Deshalb werden bei höheren Fluggeschwindigkeiten Einlässe eingesetzt, die sogenannte Stoßkonfigurationen erzeugen. Bei diesen wird die Anström-Machzahl durch einen oder mehrere verlustarme schräge Verdichtungsstöße verringert, bevor sie mit einem abschließenden senkrechten Verdichtungssto $ß$ auf Unterschallgeschwindigkeit reduziert wird. Hierbei können die schrägen Verdichtungsstöße ausschließlich vor dem Eintritt in den Einlass, ausschließlich im Einlass oder an beiden Stellen erzeugt werden 
[8, S. 284]. Dies wird im jeweiligen Fall auch als interne, externe oder gemischte Kompression bezeichnet.

Im Geschwindigkeitsbereich von Mach 1,4 bis 2,5 sind Einlässe mit externer Kompression geeignet [7], [8, S. 284], [46]. Häufig werden hierfür rechteckige Einlässe, wie bei der Concorde, der Tupolev Tu-144 oder der Rockwell B-1 Lancer, eingesetzt [11, S. 176], [46], vgl. Abbildung 2.3 oben. Dieser Einlasstyp erzeugt meist zwei bis drei Verdichtungsstöße [8, S. 284], [46]. Über bewegliche Rampen und Klappen werden die Winkel der Verdichtungsstöße und der zugeführte Massenstrom gesteuert sowie die Dicke der Strömungsgrenzschicht reguliert [46]. Die Triebwerke der besagten Flugzeuge sind bauraumbedingt paarweise unter dem Flügel angeordnet. Daraus resultiert die Gefahr von Interaktionen zwischen den benachbarten Triebwerken im Fall von Verdichterpumpen und beim Versagen des Containments [46]. Zusätzlich stellt auch der Lärm, der bei der Umströmung der Klappen erzeugt wird, einen beachtlichen Nachteil dieses Einlasstyps dar [46].

Bei Fluggeschwindigkeiten über Mach 2,2 erreichen Einlässe mit interner und gemischter Kompression eine größere Effizienz [8, S. 284], [46], vgl. Abbildung 2.3 unten. Diese benötigen komplexere Variationsmechanismen, wofür drei Varianten verbreitet sind [46]. Die beste Variante bezüglich Länge und Masse stellen axial verschiebbare konische Zentralkörper vor dem Fan dar [82, S. 29]. Diese werden mit einer rotationssymmetrischen Gondel kombiniert. Durch die konische Geometrie und die Lage des Zentralkörpers werden die auftretenden Verdichtungsstöße entsprechend der Flugphase eingestellt [46]. Als Schwachstelle dieser Technologie wird das hohe Risiko für ein Blockieren des Strömungskanals durch aerodynamische Störungen identifiziert [82, S. 8], [46]. Eine weitere Variante besteht in der Durchmesservariation des konischen Zentralkörpers kombiniert mit einer rotationssymmetrischen Gondel. Die Durchmesservariation wird dabei durch überlappende Segmente erreicht und erfordert eine hohe Komplexität der Konstruktion [46], [82, S. 8]. Jedoch ermöglicht diese Bauart eine vergleichsweise geringe Einlasslänge und die besten aerodynamischen Eigenschaften [46]. Von beiden Varianten existieren Ausführungen, bei denen der Einlass und der Zentralkörper sehr nah am Flugzeugrumpf befestigt sind und nur einen Sektor von $180^{\circ}$ oder $90^{\circ}$ umfassen [11, S. 176]. Eine sehr zuverlässige und effiziente, wenngleich lange und schwere, dritte Variante stellen zweidimensional gegabelte Einlässe (Two-dimensional Bifurcated) mit geteilten Rampen dar [46], [82, S. 8].

Für den Hyperschallbereich werden die äußere Mehrstoßverdichtung und die kontinuierliche Verdichtung empfohlen [8, S. 284]. 
Einlässe für Stoß-Konfigurationen

Concorde-Einlässe

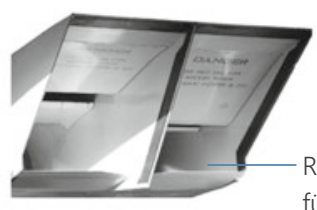

für externe Kompression

MiG-21F

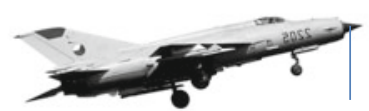

Variable Zentralkörper

für gemischte Kompression

\section{Externe Kompression in rundem Einlass}



Gemischte Kompression



- Schräger Verdichtungsstoß

- Senkrechter Verdichtungsstoß

Abbildung 2.3 Anwendungen für Einlässe mit Stoßkonfigurationen [A4]. In Anlehnung an [7], [8, S. 252, 285], [70, S. 641]

\subsection{Gestaltung von Pitot-Einlässen}

\subsubsection{Aerodynamische Gestaltung}

Das primäre Ziel bei der aerodynamischen Gestaltung des Einlasses ist es, den freien Luftstrom vor dem Flugtriebwerk am Staupunkt in einen internen und einen externen Luftstrom zu unterteilen [10, S. 941]. Der äußere Luftstrom soll entlang der äußeren Gondeloberfläche strömen, wobei Ablösungen der Strömung zu vermeiden und der Luftwiderstand zu minimieren sind [62]. Der innere Luftstrom muss dem Flugtriebwerk die erforderliche Luftmenge mit einer gewünschten Strömungsgeschwindigkeit und Gleichförmigkeit in jedem Betriebszustand zuführen und dabei aerodynamische Verluste eingrenzen [10, S. 941], [34, 25.1091], [66]. Zudem sollten die Länge und die Dicke des Einlasses kleinstmöglich sein, um seine Masse zu minimieren [12].

Die Abgrenzung zwischen innerem und äußerem Luftstrom wird im Bereich zwischen der unbeeinflussten Luft vor dem Triebwerk und der Eintrittsebene in das Triebwerk durch das Modell der Fangstromröhre beschrieben, vgl. Abbildung 2.4. Die Grenze zwischen innerem und äußerem Luftstrom wird auf der 
Einlassoberfläche durch den Staupunkt markiert. Dieser definiert den Eintrittsquerschnitt des Einlasses $A_{1}$ und befindet sich näherungsweise an der Vorderkante des Einlasses.

\section{Schnittansicht Pitot-Einlass}

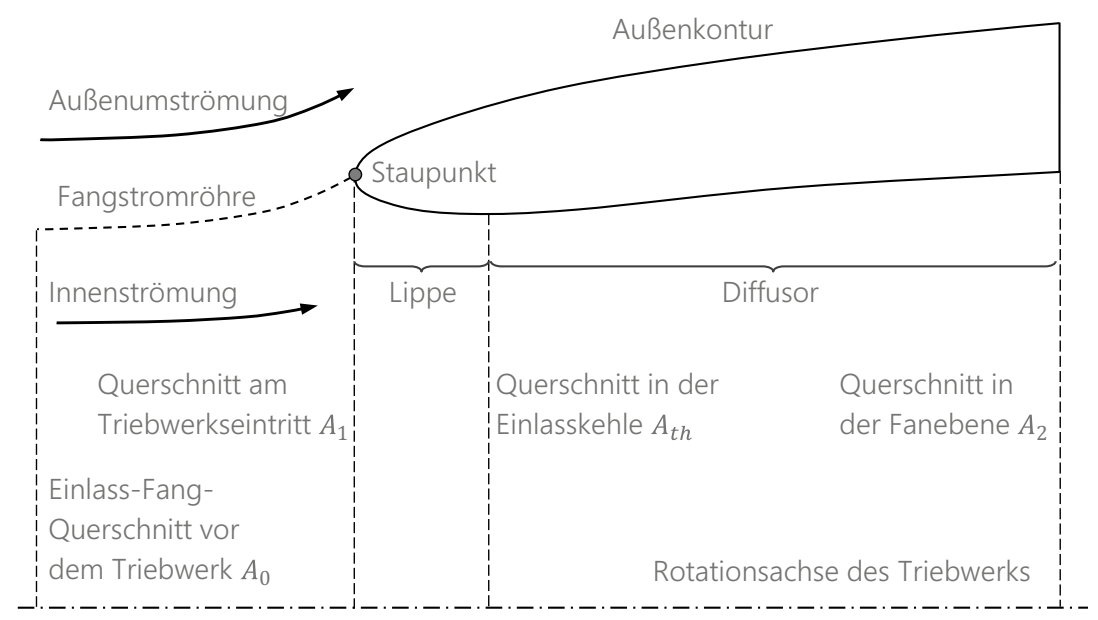

Abbildung 2.4 Ebenen eines Pitot-Einlasses

Die Geometrie der Fangstromröhre und die Lage des Staupunktes hängen stark von der Geschwindigkeit und dem Anstellwinkel des Flugzeugs, dem Betriebszustand des Triebwerks und den Umgebungsbedingungen, wie Seitenwinden, ab [10, S. 941], [11, S. 290-291]. Dies hat einen entscheidenden Einfluss auf die geometrische Gestaltung des Pitot-Einlasses.

Zwischen der Vorderkante des Einlasses und seinem engsten Querschnitt $A_{t h}$ in der Einlasskehle (Inlet Throat) nimmt der Kanal für die interne Strömung im Durchmesser ab. Dieser konvexe Bereich wird als Einlasslippe bezeichnet. Die Einlasslippe beschreibt eine näherungsweise elliptische Bahn, die eine unzulässig große Beschleunigung der Strömung und ein Ablösen der Grenzschicht verhindern soll [12].

Der engste Querschnitt $A_{t h}$ wird in Abhängigkeit lokaler Geschwindigkeitsspitzen dimensioniert. Diese sollten die Schallgeschwindigkeit nicht erreichen, da andernfalls kompressible Effekte und Strömungsablösungen auftreten können. 
Dadurch kann die Funktionsfähigkeit des Einlasses und die Effizienz bei der Umwandlung von kinetischer Energie in Druckenergie negativ beeinflusst werden. Deshalb ist die radial gemittelte Machzahl im Bereich der Einlasskehle $M a_{t h, a v g}$ auf Maxima von 0,7 bis 0,8 zu begrenzen [10, S. 942], [47, S. 339], [62], [83]. Basierend auf dieser maximal erlaubten Machzahl $M a_{t h, a v g, \max }$ und dem vom Triebwerk geforderten Luftmassenstrom, können die verlustarmen Abmessungen des engsten Querschnitts $A_{t h}$ bestimmt werden [47, S. 340].

Insbesondere im schnellen Reiseflug muss der Luftmassenstrom verlangsamt werden, um die maximale Effizienz des Fans zu gewährleisten. Die maximale Effizienz wird erreicht, indem die relative Anström-Machzahl des Fans im Gehäusebereich im Unterschall- oder moderatem Überschallbereich bis Mach 1,4 verbleibt [10, S. 944]. Dies wird durch maximale axiale Anströmgeschwindigkeiten des Fans bis Mach 0,6 gewährleistet [7], [10, S. 944]. Zwar werden bei vereinzelten Anwendungen in Abhängigkeit des Fandurchmessers und seiner Drehzahl auch Werte bis Mach 0,7 umgesetzt [8, S. 267], die üblicherweise realisierte Machzahl beträgt jedoch Mach 0,5 [61]. Die Verzögerung der Strömung zwischen den Ebenen der Einlasskehle $A_{t h}$ und dem Fanquerschnitt $A_{2}$ wird durch eine kontinuierliche Querschnittserweiterung des dazwischen liegenden Strömungskanals erreicht. Aufgrund dieser Geometrie wird dieser Kanal üblicherweise als Diffusor bezeichnet [47, S. 329].

\section{Lippenkontur}

Bei der Bestimmung der Einlasskontur müssen unterschiedliche Anforderungen erfüllt werden, um einen zuverlässigen Betrieb bei gleichzeitig hoher Effizienz zu gewährleisten [10, S. 966-967], [11, S. 12-15]. Diese Anforderungen resultieren in gegensätzlichen idealen Konturen für unterschiedliche Flugzustände [8, S. 267], [10, S. 966]. Zum einen ist es notwendig, Strömungsablösungen und potenziell daraus resultierende gefährliche Ereignisse zu vermeiden. Diese können insbesondere beim Start und beim Steigflug bis Mach 0,3 auftreten. Zum anderen soll der Einlass im Reiseflugbetrieb bei hohen Fluggeschwindigkeiten über Mach 0,8 einen minimalen Luftwiderstand erzeugen.

Bei in Betrieb befindlichem Triebwerk und verhältnismäßig geringen Fluggeschwindigkeiten im Bereich kleiner Mach 0,3 ist der Fangstromröhrenquerschnitt $A_{0}$ deutlich größer als der Einlasseintrittsquerschnitt $A_{1}$ [10, S. 987]. Dadurch ist das Flächenverhältnis $A_{0} / A_{1}$ größer als eins, wodurch sich der Staupunkt auf der Außenkontur des Einlasses befindet [10, S. 987], [11, S. 290-291], vgl. Abbildung 2.5 oben rechts. Mit abnehmender Flugmachzahl befindet sich der Staupunkt bei konstanter Triebwerksleistungsstufe zunehmend weiter auf der Außenkontur [10, S. 988]. Bei der Einströmung in den Einlass wird folglich ein Teil 
des Luftstroms von der Außenkontur um die Einlasslippe herum umgelenkt und beschleunigt. Dabei können abhängig von der Lippengeometrie auf der Innenseite der Lippe verlustbehaftete lokale Überschallgeschwindigkeiten von bis $\mathrm{zu}$ Mach 1,65 auftreten [10, S. 988].

In Flugphasen, wie dem Starten, dem Rotieren, dem Steigflug, dem Landen oder dem Abfangen, treten zusätzlich Anstellwinkel zwischen Strömung und Triebwerksachse auf [10, S. 989], vgl. Abbildung 2.5 oben mittig. Diese Anstellwinkel führen insbesondere im Bereich der unteren Einlasslippe zu einer starken Beschleunigung der Strömung und lokalen Überschallgeschwindigkeiten [10, S. 989]. Seitenwindeinflüsse haben einen ähnlichen Effekt auf die jeweils betroffene Seite des Einlasses und können einen rollenden Start (Rolling Take-Off) erforderlich machen [10, S. 173].

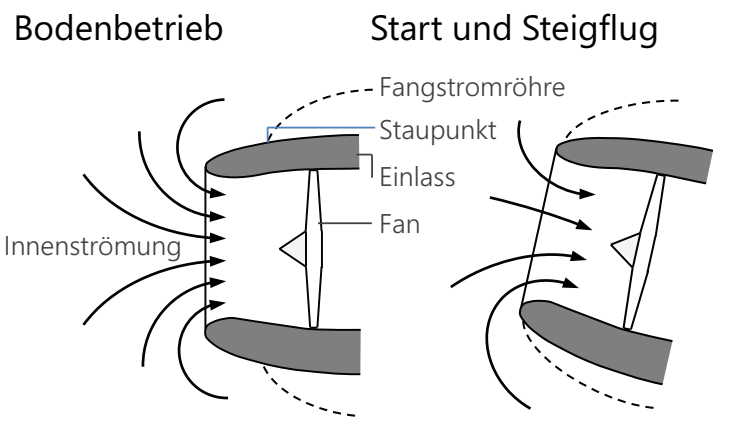

Langsamflug

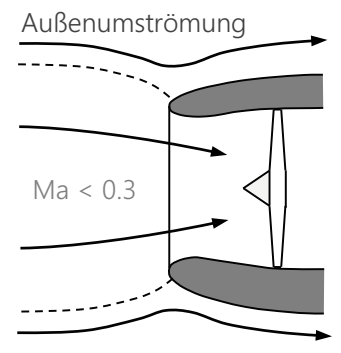

Unterschallreiseflug Windmilling
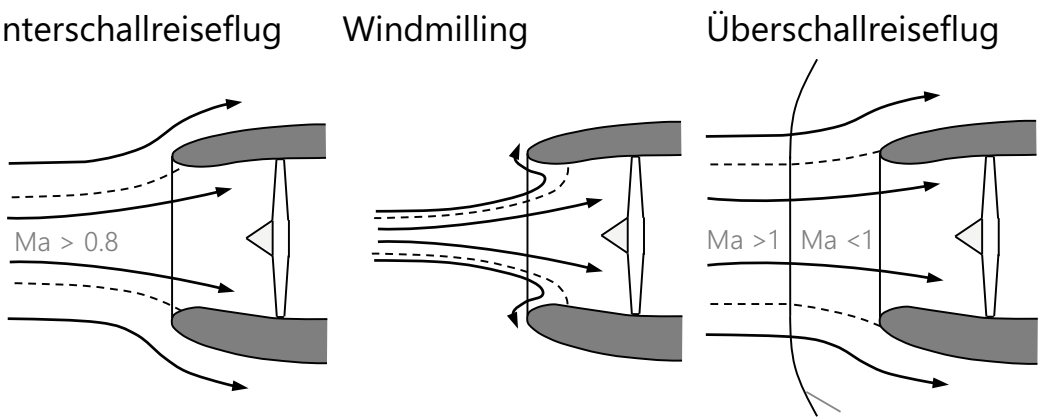

Abgelöster Verdichtungsstoß

Abbildung 2.5 Fangstromröhre während ausgewählter Flugzustände 
In Abhängigkeit der umströmten Lippenkontur können aufgrund lokaler Überschall-Machzahlen Verdichtungsstöße auftreten [10, S. 989], [11, S. 310], [84]. Diese sind mit einem Anwachsen der Grenzschicht verbunden und können in Ablöseblasen, ausgeprägten Strömungsablösungen und Wirbelzöpfen resultieren [10, S. 989], [84]. Daraus können Schaufelanregungen und Verdichterpumpen folgen, was gefährliche Ereignisse nach sich ziehen kann, falls mehrere Triebwerke betroffen sind [10, S. 990], [11, S. 307-311], [34].

Zwar kann die Gefahr von Strömungsablösungen und daraus resultierenden Inhomogenitäten der Fananströmung nicht vollständig umgangen werden, jedoch empfiehlt die Literatur [10, S. 172], [11, S. 100], [12], [47, S. 341] die Verwendung dicker Einlasslippen mit großem Rundungsradius (Blunt Lips) für die genannten langsamen Flugphasen, vgl. Abbildung 2.6 links. Die Geometrie dicker Einlasslippen ist vergleichbar mit hocheffizienten Glockeneinlässen (Bell Mouth Inlets), die in Triebwerksprüfständen Anwendung finden [10, S. 178-179]. Im Vergleich zu dünnen oder scharfen Einlasslippen, vgl. Abbildung 2.6 rechts, treten bei dicken Lippen aufgrund der größeren Rundungsradien kleinere lokale Machzahlen sowie weniger Verdichtungsstöße und Strömungsablösungen auf [10, S. 172]. Dadurch sind dicke Einlasslippen in diesen Flugphasen auch deutlich effizienter [8, S. 266]. Quantifiziert wird die Dicke der Lippe zumeist durch das Kontraktionsverhältnis (Contraction Ratio) [11, S. 315-316], [47, S. 341]. Dieses wird im späteren Verlauf dieser Arbeit genauer erläutert, vgl. Abschnitt 4.4.3.

\section{Dicke Einlasskontur}

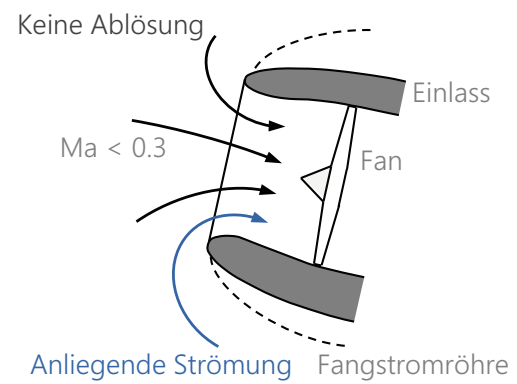

Dünne Einlasskontur



Abbildung 2.6 Ablöseverhalten beim Start und Steigflug

Während dicke Einlasslippen bei langsamen Fluggeschwindigkeiten gut geeignet sind, erzeugen sie beim schnellen Reiseflug zu viel Luftwiderstand [47, 
S. 341]. Bei diesen höheren Fluggeschwindigkeiten wird der Fangstromröhrenquerschnitt kleiner und der Staupunkt wandert von der Außenseite des Einlasses nach innen [10, S. 941], [11, S. 290-291], vgl. Abbildung 2.5 unten links. Dadurch wird der äußere Luftstrom entlang der Lippenkontur von innen nach außen geleitet und dabei beschleunigt. Infolgedessen treten auf der Außenseite dicker Einlasskonturen Überschallgeschwindigkeiten auf, die in Verdichtungsstößen und Verlusten resultieren [10, S. 172], vgl. Abbildung 2.7. Eine dünne Einlasslippe erzeugt bei den Betriebsbedingungen des schnellen Unterschallreiseflugs geringere aerodynamische Verluste und einen niedrigeren externen Widerstand [10, S. 172], [12], [47, S. 341].

Beim Ausfall eines Triebwerks mit weiterhin durch den Wind angetriebenem Rotor, auch als Windmilling bekannt, vgl. Abbildung 2.5 unten mittig, und besonders im Fall eines mechanisch blockierten Rotors ist der Triebwerksmassenstrom signifikant reduziert. Dadurch ist auch die Fangstromröhre deutlich kleiner als im Reiseflug und es treten auf der Außenseite des Einlasses Strömungsablösungen und zusätzlicher Strömungswiderstand auf [10, S. 173]. Um die Folgen dieser Zustände abzuschwächen, wäre eine deutliche Verkleinerung des Eintrittsquerschnitts des Einlasses sinnvoll.

Dicke Einlasskontur

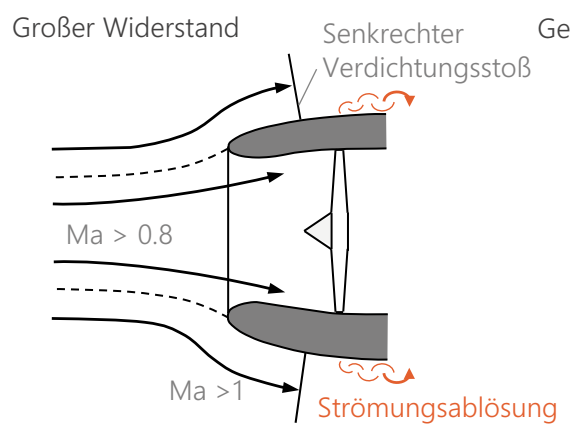

\section{Dünne Einlasskontur}

Geringer Widerstand

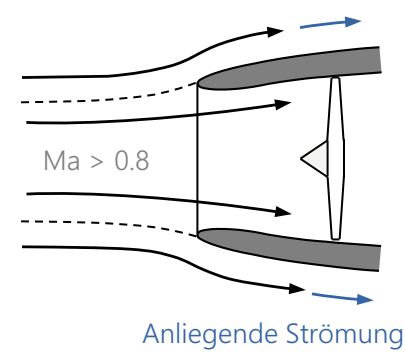

Abbildung 2.7 Luftwiderstand im Unterschallreiseflug

Für den Überschallreiseflug bis Mach 1,6 wird bei der Verwendung von PitotEinlässen eine scharfe Lippe empfohlen [11, S. 127], [47, S. 359-360]. Dies begründet sich aus der kleineren Profilfläche und dem Einfluss der Form eines Körpers auf Lage und Stärke des entstehenden Verdichtungsstoßes [10, S. 1875], 
[85, S. 533]. Je schärfer die Lippe gestaltet ist, umso näher kann der Verdichtungsstoß an die Einlasskontur heranrücken und umso geringer ist der resultierende Strömungswiderstand [85, S. 533], vgl. Abbildung 2.8.
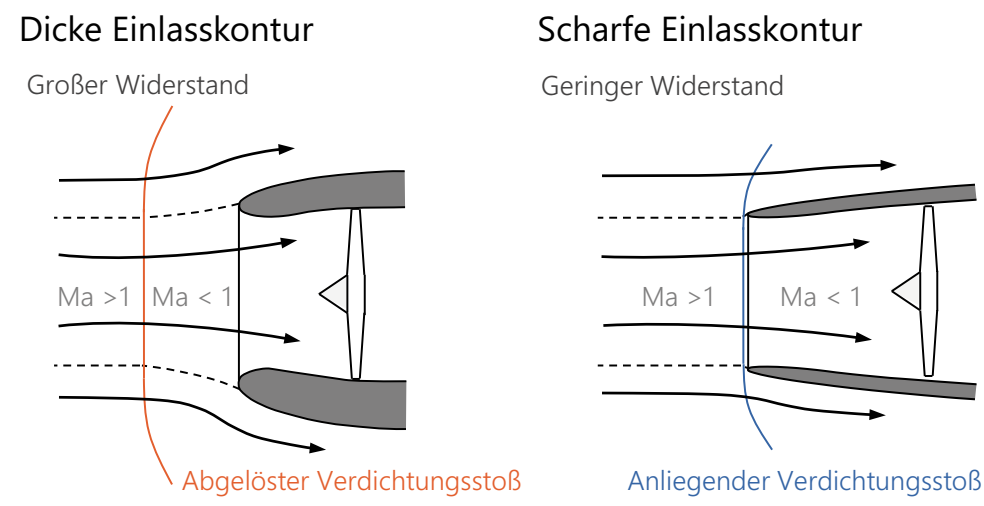

Abbildung 2.8 Luftwiderstand im Überschallreiseflug

Im Idealfall befinden sich dabei die Stoßwelle und die Einlasskehle in der Vorderkante, wodurch instabile Effekte, wie das Starten des Einlasses [10, S. 993994], vermieden werden können [47, S. 359-360]. Jedoch kann auch eine Lippe mit einer leichten Rundung weiterhin niedrigen Widerstand erzeugen und bei hohen Überschallgeschwindigkeiten sogar erforderlich werden, um den Effekt aerodynamischer Reibungswärme etwas zu lindern [11, S. 239]. So kann beim Überschallflug bei Mach 2,2 von Oberflächentemperaturen von etwa $120^{\circ} \mathrm{C}$ ausgegangen werden und im Hyperschall bei Fluggeschwindigkeiten über Mach 5,0 von bis zu $1800{ }^{\circ} \mathrm{C}$ [86], [87].

Die Auslegung einer starren Einlasslippe kann folglich nur einen Kompromiss hinsichtlich des minimalen Widerstandes bei hohen Geschwindigkeiten und der Vermeidung von Strömungsablösung bei niedrigen Geschwindigkeiten darstellen [10, S. 173], [12]. Luidens et al. [12] beschreiben die historische Herangehensweise bei der Identifikation der idealen Kompromissgeometrie starrer subsonischer Einlässe im Rahmen von Untersuchungen bezüglich Senkrechtstarterkonzepten in den 70er Jahren des letzten Jahrhunderts.

So setzen erste Arbeiten von Albers et al. [88], [89] den Fokus auf die Vermeidung von Ablösungen. Dafür werden für mehrere Strömungszustände die 
Geschwindigkeitsverteilungen der Kandidatengeometrien ermittelt [12]. Die Auswahl der Geometrie erfolgt basierend auf der niedrigsten maximalen lokalen Machzahl [12]. Somit werden mit diesem Ansatz sehr konservative Geometrien ausgewählt [12]. Aus diesem Grund bestimmen Boles und Stockman [90] eine maximal zulässige lokale Machzahl. Diese Begrenzung nutzen die Ansätze von Boles et al. [91] sowie Hawk und Stockmann [92], indem die maximalen lokalen Geschwindigkeiten mehrerer Geometrien verglichen werden [12]. Hierbei wird die Geometrie ausgewählt, die die höchste maximale Geschwindigkeit aufweist, die kleiner als die maximal zulässige lokale Machzahl ist [12]. Dies resultiert in kürzeren und dünneren Einlasslippen. Der Ansatz von Luidens et al. [12], [93] ist vergleichbar mit den Ansätzen von Smith [94] und Liebeck [95] bezüglich subsonischer Hochauftriebs-Strömungsprofile. Hierbei werden neben der lokalen Machzahl auch die Wandschubspannungen untersucht. Diese sollen minimal sein, aber weiterhin positiv, da andernfalls Strömungsablösungen auftreten [93].

Arbeiten der jüngeren Vergangenheit [13], [14], [15], [16], [17], [18], [20] fokussieren sich vorrangig auf die automatisierte Identifikation von Einlassgeometrien unter Verwendung von Strömungssimulationen. Dabei werden beispielsweise unterschiedliche Geometrieparametrisierungen, Herangehensweisen zur Widerstandsbestimmung, Verfahren zur Bestimmung des Ablöseverhaltens und Optimierungsalgorithmen verwendet.

Die Auslegung moderner Unterschall-Einlässe erfolgt vorrangig für den Reiseflug [8, S. 266], [11, S. 290], [66, S. 232]. Dadurch kann unter anderem die behördlich geforderte Ablöseresistenz bei Seitenwind beeinträchtigt werden, was in Einschränkungen des Betriebs, wie dem rollenden Start, resultieren kann [10, S. 173]. Um solche negativen Folgen zu vermeiden, werden im Rahmen der Einlassentwicklung zahlreiche numerische Strömungsuntersuchungen und Windkanaltests durchgeführt [10, S. 983], [66, S. 233].

\section{Diffusorkontur}

Die Diffusorgeometrie soll bei minimaler Länge die effiziente und ablösungsfreie Umwandlung der Geschwindigkeitsenergie in statischen Druck ermöglichen [47, S. 329]. Die Länge des Diffusors hat einen entscheidenden Einfluss auf die sich ausbildende Grenzschicht und somit das Ablöseverhalten, die Effizienz und die Gleichförmigkeit [8, S. 284]. Lange Diffusoren können Grenzschichtbeeinflussung, wie beispielsweise Grenzschichtabsaugung, erforderlich machen [12]. Die minimale Länge ist darüber hinaus abhängig von der erforderlichen Mindestlänge für das Ausgleichen von Ungleichförmigkeiten in der Geschwindigkeitsverteilung sowie für die Integration von Akustikauskleidungen [12]. 
Die Diffusorkontur verläuft vom engsten Querschnitt ausgehend nicht linear, sondern kann durch Doppelellipsen [12] oder kubische Funktionen [96] beschrieben werden. $\mathrm{Zu}$ Beginn der Kontur sollte eine stärkere Aufweitung als im Bereich der letzten $75 \%$ des Diffusors stattfinden [12], [96]. Ein idealer Diffusor weist dabei über die gesamte Erstreckung eine minimale Wandschubspannung auf, die jedoch positiv ist [12], [96]. Negative Wandschubspannungen, die auf Strömungsablösungen hindeuten, lassen sich durch die geeignete Wahl eines mittleren Wertes für den halben Diffusoröffnungswinkel $\theta_{\text {dif }}$, vgl. Abbildung 2.9, vermeiden [10, S. 965-966].

\section{Schnittansicht Pitot-Einlass}

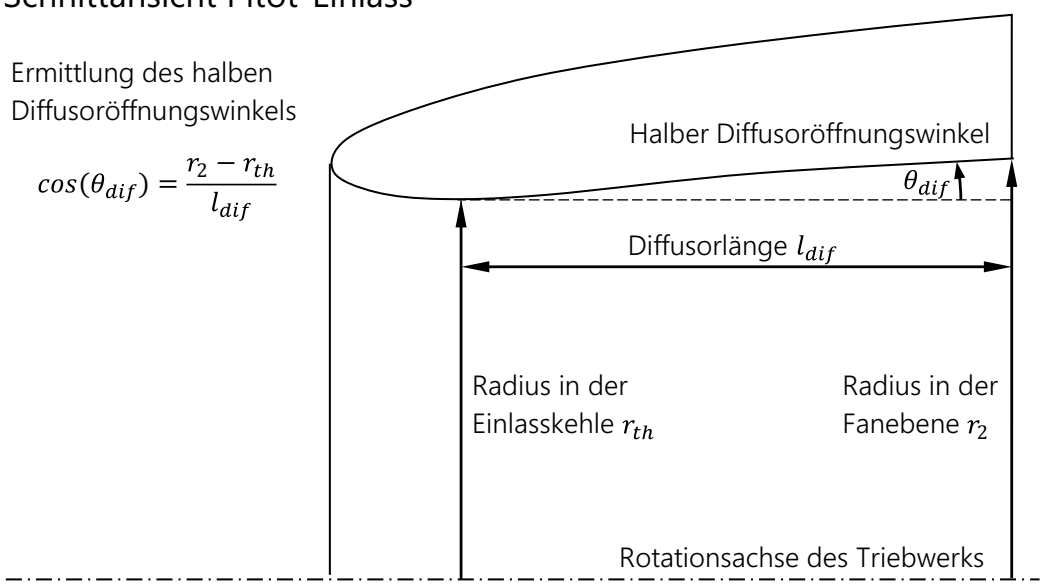

Abbildung 2.9 Diffusoröffnungswinkel eines Pitot-Einlasses

Bei konischen Diffusoren, wie sie in den meisten Pitot-Einlässen verwendet werden, entspricht der Winkel zwischen Diffusorwandung und der Rotationsachse des Triebwerks dem durchschnittlichen halben Diffusoröffnungswinkel. Der Wert des maximalen halben Diffusoröffnungswinkels $\theta_{\text {dif }}$, bei dem weiterhin keine Strömungsablösungen auftreten, wird auf $8^{\circ}$ bis $10^{\circ}$ beziffert [10, S. 965-966], [47, S. 349]. Dieser Wert hängt unter anderem von der Länge des Einlasses ab [10, S. 965-966]. 


\section{Außenkontur}

Die Gestaltung der äußeren Kontur erfolgt derart, dass der Strömungswiderstand bei der Umströmung minimiert wird. Für den schnellen Unterschallflug ist das Ziel bei der Auslegung der Außenkontur, eine Saugkraft zu generieren [10, S. 951]. Dies kann durch den Einsatz sogenannter überkritischer Profile, wie beispielsweise denen der NACA-1-Serie, erreicht werden [10, S. 984-986], [11, S. 203], [83].

Bei überkritischen Profilen befindet sich die Außenströmung im vorderen Bereich des Einlasses lokal im Überschallbereich [10, S. 985]. Aus diesem Geschwindigkeitsbereich resultieren Verdichtungsstöße, deren Verluste, beispielsweise durch Verdickung der Grenzschicht, es zu minimieren gilt [10, S. 149]. Dies wird erreicht, indem der abschließende senkrechte Verdichtungsstoß durch die Wölbung der Außenkontur stromabwärts hin zum maximalen Durchmesser der Triebwerksgondel verlagert wird. Somit hat die Erhöhung des statischen Drucks nach dem Verdichtungsstoß nur minimale Auswirkungen auf den Widerstand der Gondel [10, S. 985].

Die Kontur überkritischer Profile weist im Bereich der Vorderkante eine stark konvexe Krümmung oder Wölbung auf [10, S. 985]. Diese hat eine Umlenkung der Strömung zur Folge und resultiert in einer Beschleunigung auf lokale Machzahlen von bis zu Mach 1,65 [10, S. 985]. Die Umlenkung wird zudem dadurch verstärkt, dass der Staupunkt mit steigender Fluggeschwindigkeit zunehmend auf der Innenseite des Einlasses befindlich ist [10]. Mit der erreichten Geschwindigkeitserhöhung ist ein Absinken des statischen Druckes unter das Niveau des Umgebungsdruckes verbunden. Dadurch entsteht eine Saugkraft bei der Umströmung. Der anschließende Bereich der Außenkontur bis hin zum maximalen Querschnitt der Gondel hat eine geringe Wölbung. Somit treten auf der Außenkontur nur schwache schräge Verdichtungsstöße auf. Dadurch wird im Idealfall eine verlustfreie Verzögerung der Strömung erreicht, wodurch auch der abschließende senkrechte Verdichtungsstoß möglichst schwach und verlustarm ist [10, S. 984-985], [97, S. 59].

Bei Überschallanwendungen findet vor dem Einlass ein senkrechter Verdichtungsstoß statt. Dieser erhöht den statischen Druck auf der Außenkontur deutlich über das Umgebungsniveau, sodass keine Saugkraft erzeugt werden kann. Deshalb wird der Widerstand bei Überschall-Pitot-Einlässen durch eine Minimierung der Profilfläche mittels einer scharfen Lippe und einer möglichst geringen Wölbung der Außenseite erreicht [47, S. 359]. 


\subsubsection{Konstruktive Gestaltung}

Bei der Materialauswahl für den Einlass werden typischerweise Leichtbaumaterialien berücksichtigt [66, S. 234]. So wird die Lippe üblicherweise aus Aluminium, die Außenbeplankung aus Kohlefaserverbundmaterialien und die Diffusorwandung unter anderem aus Aluminiumverbundwerkstoffen gefertigt [66, S. 234]. Bei der Lippe fällt die Wahl auf Aluminium, da es einerseits widerstandsfähig gegen die auftretenden mechanischen Belastungen und andererseits aufgrund seiner guten Wärmeleitungseigenschaften kompatibel mit Vereisungsschutzmechanismen im Bereich der Einlasslippe ist.

Strahltriebwerke verwenden für den Schutz vor Vereisung vorrangig Systeme, die mit heißer Zapfluft aus dem Hochdruckverdichter gespeist werden [66, S. 242], [67, S. 147]. Hierbei wird die Zapfluft über Rohrleitungen und Ventile in ein umlaufendes perforiertes Rohr in der Einlasslippe geleitet [67, S. 147-149], vgl. Abbildung 2.10. Durch die Löcher dieses Rohrs tritt die heiße Zapfluft aus und erwärmt die Einlasslippe [67, S. 147-149]. Für dieses Enteisungssystem wird Stahl als Material eingesetzt [66, S. 234]. Bei Turboprop-Triebwerken finden häufig elektrische Enteisungssysteme Anwendung [66, S. 242]. Diese werden in Form von Heizmatten in die Einlasshülle integriert [66, S. 242], [67, S. 150]. Auf die Detektion und die Vermeidung von Vereisung wird in Abschnitt 2.3 ausführlich eingegangen.

\section{Schnittansicht Pitot-Einlass}

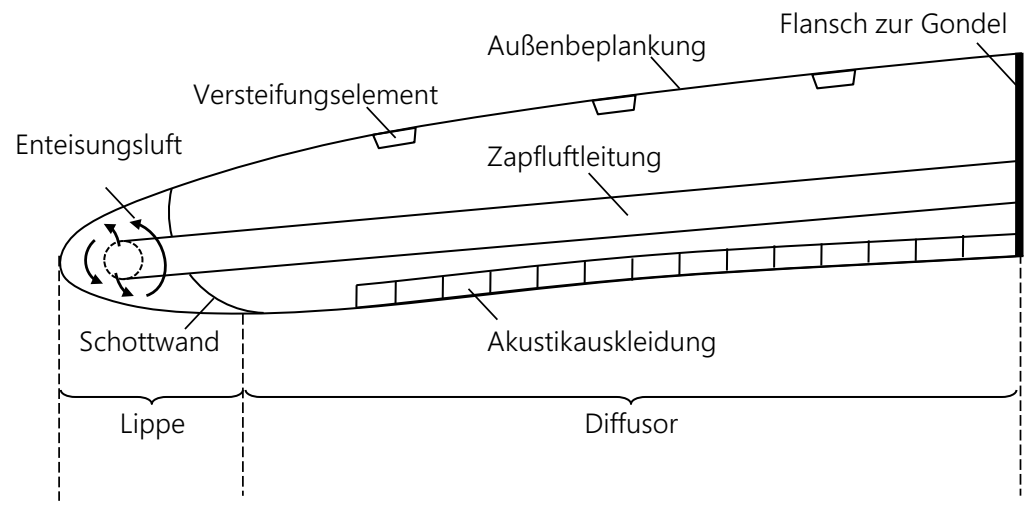

Abbildung 2.10 Komponenten eines Pitot-Einlasses 
Die Diffusorwandung beinhaltet schallabsorbierende Auskleidungen, um die vom Fan ausgehende Lärmbelastung für die Umwelt zu reduzieren [66, S. 62/233234]. Die Akustikauskleidungen verfügen über eine perforierte Abdeckung und einen wabenförmigen Kern, in dem eindringende Schallwellen ausgelöscht werden [66, S. 62/233-234]. Zudem haben diese Akustikauskleidungen den Effekt der strukturellen Versteifung. Eine strukturelle Verstärkung der dünnen Außenhülle wird durch umlaufende Versteifungselemente erreicht [66, S. 234]. Der Einlass wird zumeist über eine geschraubte Flanschverbindung mit dem Fan-Gehäuse und somit der restlichen Gondel verbunden [66, S. 233]. Weiterhin sind Sensoren zur Ermittlung des statischen Drucks $p_{2}$, des Totaldrucks $p_{t 2}$ und der Totaltemperatur $T_{t 2}$ vor dem Fan in den Einlass integriert [77, S. 579-581].

Über den Umfang des Einlasses werden häufig verschiedene Schnittgeometrien (Cross Sections) eingesetzt, die sanft ineinander übergehen [10, S. 173-174], [12], [15], vgl. Abbildung 2.11. Dies erfolgt, um für die wirkenden Bedingungen in den einzelnen Bereichen des Einlasses eine effiziente und sichere Geometrie bereitzustellen [12]. So wird für den unteren Sektor des Einlasses eine dicke Geometrie mit großem Rundungsradius gewählt, um starke Strömungsablösungen bei großen Anstellwinkeln zu vermeiden [10, S. 173-174], [12]. Dies unterstützt zudem die Unterbringung von Hilfsaggregaten im unteren Bereich der Triebwerksgondel [10, S. 173-174]. Die seitlichen Einlasssektoren sind gegen Seitenwindeinflüsse auf der Rollbahn ausgelegt und der obere Sektor für minimalen Widerstand im Reiseflug [10, S. 173-174], [12].
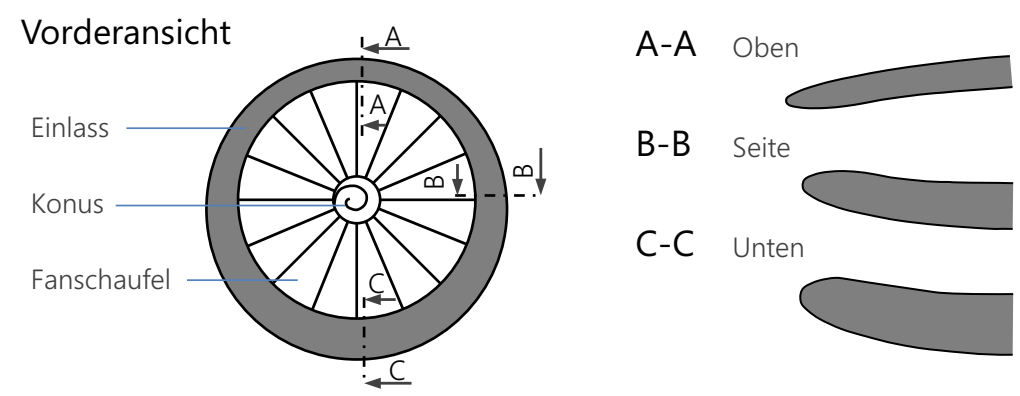

Abbildung 2.11 Schnittgeometrien über den Umfang des Einlasses 


\subsubsection{Sonderbauformen}

Um zur Erfüllung der jeweiligen Anforderungen an die zugehörige Anwendung beizutragen, existieren zahlreiche Bauformen von Pitot-Einlässen, die von der Regel abweichen. Ein Beispiel hierfür stellt der Einlass des CFM56-Triebwerks der Boeing B737-300 dar [10, S. 982]. Dieser ist im unteren Bereich abgeflacht, um genügend Abstand zum Boden gewährleisten zu können und somit die Gefahr des Einsaugens von Fremdkörpern auf der Rollbahn zu reduzieren [10, S. 982], vgl. Abbildung 2.12 links.
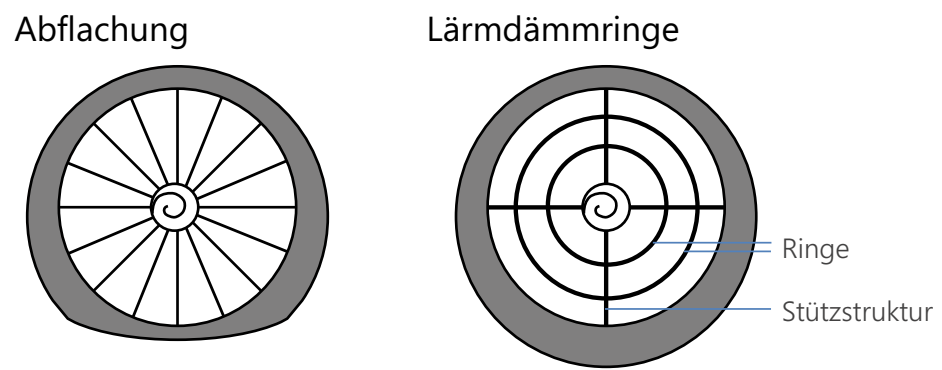

Abbildung 2.12 Abflachung des Einlasses und integrierte Ringe

Weiterhin existieren zahlreiche Konzepte der Lärm- und Strömungsbeeinflussung. So könnten Ringe in den Einlass integriert werden, welche mit Akustikauskleidungen versehen sind, um den Lärm zu reduzieren [9], vgl. Abbildung 2.12 rechts. Gleichzeitig könnten solche Ringe zur Gleichrichtung der Strömung verwendet werden [98]. Bisher wurden diese Anwendungen allerdings aufgrund der hohen erforderlichen Masse nicht eingesetzt [9].

Viele Pitot-Einlässe sind darüber hinaus auf der Unterseite kürzer als auf der Oberseite, vgl. Abbildung 2.13 links. Diese Bauart wird auch bei anderen Einlasstypen, wie beispielsweise den rechteckigen Einlässen der Concorde, verwendet, vgl. Abbildung 2.3. Durch diesen positiven Schräganschnitt (Scarf, Stagger, Rake) wird die Umlenkung um die untere Lippe reduziert und somit die Eintrittswahrscheinlichkeit von Strömungsablösungen verringert [11, S. 318-321]. Umgekehrt existieren auch Studien über Einlässe mit negativem Schräganschnitt (Negative Scarfed Inlets), die den im Triebwerk entstehenden Schall nach oben hin ablenken [9], [99]. Dadurch wird der am Boden wahrnehmbare Lärm reduziert. Jedoch ist dieses Konzept sehr anfällig für Strömungsablösungen im Bereich der unteren Einlasslippe [9]. 
Positiver Schräganschnitt

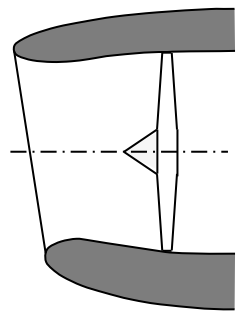

Negativer Schräganschnitt

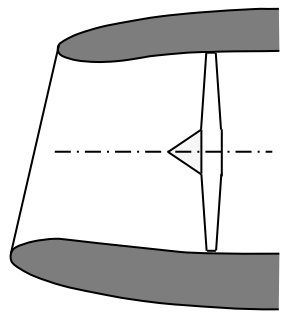

Abbildung 2.13 Schräganschnitt von Pitot-Einlässen

Strömungsablösungen werden bei Überschalleinlässen auch durch die Verwendung von Systemen zur Luftabscheidung, wie Öffnungsklappen oder Jalousieöffnungen, vermieden [10, S. 1010-1012]. Dabei wird überschüssige Luft aus dem Triebwerk ausgeleitet [10, S. 1010-1012]. Umgekehrt kann bei langsamen Flugzeuggeschwindigkeiten durch diese Öffnungen auch zusätzliche Luft in das Triebwerk eingeleitet werden [10, S. 1010-1012]. Ein ähnlicher Effekt kann bei Unterschallanwendungen genutzt werden, um bei niedrigen Geschwindigkeiten genügend Luft bei minimalen Druckverlusten und Strömungsstörungen in den Einlass hineinströmen zu lassen [8, S. 268-269]. Hierbei werden über den Umfang verteilte Klappen oder Schlitze bei langsamen Geschwindigkeiten geöffnet, sodass die effektive Einlassfläche vergrößert wird [8, S. 268-269], vgl. Abbildung 2.14. Im Reiseflug werden diese Öffnungen verschlossen [9]. Anwendung fand diese Technologie bei zahlreichen Transportflugzeugen, wie beispielsweise der Boeing 707-347C mit Pratt \& Whitney JT3D-7-Triebwerken [9], [10, S. 1536]. Da bei der Umströmung der Klappen Verwirbelungen und Ungleichförmigkeiten auftreten, wird zusätzlicher Lärm erzeugt [100, S. 114]. Aus Gründen der Lärmreduktion wird diese Technologie in der kommerziellen Luftfahrt nicht mehr verwendet [62, S. w7].

Zur Vermeidung von Strömungsablösungen existieren weiterhin Konzepte für Einlässe mit variablem Lippenanstellwinkel [11, S. 317]. Diese können als gelenkig drehbare Lippen [101] oder vorgelagerte bewegliche Profile [102] ausgeführt werden [11, S. 317], vgl. Abschnitt 2.4.2.

Eine potenziell reduzierte Ausdehnung von Ablösezonen und verringerte Strömungsverluste können zudem durch eine halbkreisförmige Ausführung des 
Nebenstromklappen im geöffneten Zustand

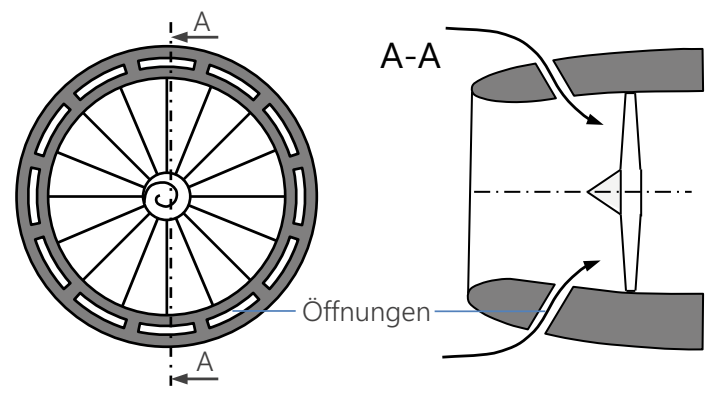

Abbildung 2.14 Nebenstromöffnungen bei Pitot-Einlässen

Pitot-Einlasses erreicht werden [11, S. 317-318]. Diese Bauweise findet vorrangig bei militärischen Überschallflugzeugen Anwendung, wie beispielsweise bei der Dassault Rafale in Abbildung 2.2.

\subsection{Einflüsse auf die Einlassgestaltung}

Die beschriebene Gestaltung von Triebwerkseinlässen spiegelt die an diese gestellten teils sehr unterschiedlichen aerodynamischen und konstruktiven Anforderungen wider. Diese Anforderungen und ihr Einfluss auf die Gestaltung sind während des Entwicklungsprozesses miteinander zu vereinen. Je nach Wichtung der Anforderungen, kann auch die Gestaltung des Einlasses sehr unterschiedlich ausfallen. Den größten Einfluss auf die Gestaltung kommerziell genutzter Triebwerkseinlässe haben

- das Einlassdruckverhältnis,

- der Strömungswiderstand,

- die Gleichförmigkeit der Strömung in der Ebene des Fans,

- die Masse,

- der vorhandene Bauraum,

- die Beständigkeit gegenüber mechanischen Belastungen, wie aerodynamischen Lasten, Vogel-, Hagel- oder Fremdkörpereinschlägen,

- der Schutz vor Vereisung,

- die erforderliche Reduktion von Schallemissionen,

- die Zuverlässigkeit, 
- Wartungsanforderungen sowie

- alle auftretenden Kostenarten [47, S. 327 ff.], [62, S. 2].

Das Einlassdruckverhältnis, die Gleichförmigkeit der Strömung und der Strömungswiderstand können als strömungsmechanische Kennzahlen der Einlassgestaltung zusammengefasst werden [11], [47]. Zudem beschreiben der Schutz vor Vereisung und Lärmminderungsmaßnahmen Zusatzfunktionen, die in den Einlass zu integrieren sind. Diese Anforderungen werden in den nachfolgenden Abschnitten ausführlich erläutert. Die übrigen Anforderungen werden in Kapitel 4 dieser Arbeit aufgegriffen.

\subsubsection{Aerodynamische Kennzahlen}

\section{Einlassdruckverhältnis}

Während des Reiseflugs verzögert der Einlass den freien Luftmassenstrom vor dem Flugtriebwerk in einen internen Luftmassenstrom mit einer niedrigeren Machzahl und einem höheren statischen Druck, um die Anforderungen des Triebwerks zu erfüllen [11, S. 9]. Bei dieser Umwandlung treten Verluste des Totaldrucks vom Freistrahl $p_{t 0}$ hin zur Fanebene $p_{t 2}$ auf. Diese Totaldruckverluste werden hauptsächlich durch folgende Faktoren verursacht:

- turbulente Durchmischung in Verbindung mit Strömungsablösung,

- Oberflächenreibung und

- kompressible Effekte, z. B. Stoßwellen [11, S. 12].

Das Einlassdruckverhältnis von $p_{t 2}$ zu $p_{t 0}$, auch als Druckrückgewinnung bekannt, wird allgemein zur Beschreibung der Effizienz der Druckumwandlung innerhalb des Einlasses verwendet [11, S. 10]:

$$
\pi_{i n l}=\frac{p_{t 2}}{p_{t 0}} .
$$

Pitot-Einlässe erreichen beim langsamen Unterschallflug Druckrückgewinnungswerte von über 0,90 [10, S. 963]. Dieser Wert kann im Unterschall mit steigender Fluggeschwindigkeit auf bis zu 0,99 ansteigen [10, S. 963]. Im Überschall sinkt der Druckrückgewinnungswert aufgrund des verlustbehafteten senkrechten Verdichtungsstoßes vor dem Pitot-Einlass auf ein theoretisches Maximum von 
- $\pi_{i n l}=0,98$ bei Mach 1,3,

- $\pi_{i n l}=0,90$ bei Mach 1,6 und

- $\pi_{i n l}=0,72$ bei Mach 2,0 [11, S. 105].

Aufgrund von Reibungsverlusten kann das Einlassdruckverhältnis zusätzlich um bis zu $3 \%$ absinken [11, S. 105]. Überschalleinlässe, die Stoßkonfigurationen mit mehreren schrägen Verdichtungsstößen und einem abschließenden senkrechten Verdichtungsstoß erzeugen, können Druckrückgewinnungswerte von 0,96 bis 0,98 bei Mach 1,6 erreichen [36]. Die Einlässe der Concorde erreichten bei Mach 2,0 eine Druckrückgewinnung von 0,95 [46].

Die Druckrückgewinnung des Einlasses beeinflusst den Schub, den ein Triebwerk erzeugen kann [11, S. 11]. Dabei entspricht ein Verlust der Druckrückgewinnung von $1 \%$ einem Schubverlust von etwa $1 \%$ bis $1,5 \%$ [11, S. 11]. Dabei kann der Schubverlust bei Geschwindigkeiten über Mach 2,0 noch stärker ansteigen [9]. Dieser Zusammenhang resultiert bei einer Fluggeschwindigkeit von Mach 1,6 in einem Schubnachteil von Pitot-Einlässen gegenüber Einlässen mit Stoßkonfigurationen von $6 \%$ bis 16,5\%. Daher werden Pitot-Einlässe bei Fluggeschwindigkeiten, die diesen Wert überschreiten, unwirtschaftlich und sind bei Mach 1,3 am besten geeignet [11, S. 105]. Bei Fluggeschwindigkeiten von Mach 1,6 muss dieser Nachteil bezüglich des reduzierten Schubs überwacht und gegen die Vorteile bezüglich des geringen Widerstands, des stabilen Betriebsverhaltens und der hohen Gleichförmigkeit der Strömung abgewogen werden [11, S. 105].

Der Einlassdruckverlust wird maßgebend durch die mittlere Machzahl im engsten Querschnitt des Einlasses bestimmt [62, S. w4]. Hierbei sollten maximale Werte im Bereich von Mach 0,7 bis 0,8 realisiert werden [62, S. w4], um Verluste durch lokale kompressible Effekte zu vermeiden.

\section{Gleichförmigkeit der Fananströmung}

Der Luftmassenstrom, der durch den Einlass zum Fan geleitet wird, muss axial ausgerichtet und über eine möglichst homogene Geschwindigkeits-, Temperaturund Druckverteilung verfügen [11, S. 266]. Die Gleichförmigkeit der Strömung im Querschnitt der Fanebene $A_{2}$ kann durch hohe Anstellwinkel, Seitenwindeinflüsse und die Gestaltung des Einlasses beeinträchtigt werden [11]. Bei Reiseflugbedingungen sind Strömungsablösungen aufgrund einer ungeeigneten Einlassgestaltung der Hauptgrund für eine inhomogene Anströmung des Fans.

Die Gleichförmigkeit in der Fanebene ist erforderlich, um Schwingungsanregungen, zusätzlichen Lärm und Strömungsablösungen des Fans zu vermeiden [9], [10, S. 967]. Diese Strömungsablösungen können zu Triebwerkspumpen und zum 
Erlöschen des Triebwerks führen sowie eine verringerte Lebensdauer der Komponenten und einen Schubverlust zur Folge haben [10, S. 967], [65], [103]. Das Ausmaß dieser möglichen Auswirkungen ist primär von der Stärke und Dauer der Ungleichförmigkeit sowie der Größe des betroffenen Einlasssektors abhängig [103, S. 378-379].

Gewisse radiale Ungleichförmigkeiten in der Druck- und Geschwindigkeitsverteilung der Fananströmung sind aufgrund der Grenzschicht des Diffusors stets vorhanden [11, S. 269]. Die Grenzschicht hat im untersuchten Geschwindigkeitsbereich jedoch nur einen geringen Einfluss auf den Wirkungsgrad und eine vernachlässigbare Auswirkung auf die Pumpgefahr des Fans [11, S. 269], [103, S. 379].

Ungleichförmigkeiten über den Umfang haben in der Fananströmung einen größeren Einfluss als radiale, da sie in Verbindung mit der Rotation des Fans eine variierende aerodynamische Belastung der Fanschaufeln hervorrufen [11, S. 269], [103, S. 379]. Obwohl die detaillierten Auswirkungen dieser Ungleichförmigkeit noch nicht vollständig verstanden sind [65], stellt das Modell der parallelen Verdichter von Pearson und McKenzie [104] ein allgemeinhin akzeptiertes Modell für die Approximation der transienten Umfangsungleichförmigkeit von Verdichtern dar [11, S. 269-270], [103, S. 380-382], [105], [106]. Da der Fan ein einstufiger Verdichter ist, kann dieses Modell auch für die Ungleichförmigkeit der aus dem Einlass resultierenden Fananströmung angewendet werden [11, S. 269-270].

Das Modell der parallelen Verdichter unterteilt den untersuchten Verdichter in zwei separate identische Teilverdichter mit gleicher Drehzahl, aber unterschiedlichen Eintrittsbedingungen, um die Auswirkungen der Ungleichförmigkeit zu bestimmen [104]. Einer der Teilverdichter hat als Eintrittsbedingung den niedrigen Totaldruck des gestörten Gebiets $p_{t 2, \text { gestört }}$. Der andere Teilverdichter spiegelt den höheren Totaldruck des ungestörten Bereichs $p_{t 2, \text { ungestört }}$ wieder [11, S. 269270], [105]. Es wird weiterhin angenommen, dass die Teilverdichter den gleichen statischen Austrittsdruck $p_{3}$ erzeugen [11, S. 269-270], [103, S. 380-382], [105].

Da alle Fanschaufeln mit der gleichen Drehzahl rotieren, müssen die Schaufeln, die von einem gestörten Gebiet niedrigeren Totaldrucks angeströmt werden, mehr Arbeit verrichten als die Schaufeln in Gebieten höheren Drucks [11, S. 269270]. Daraus resultiert ein erhöhtes Druckverhältnis $p_{3} / p_{t 2}$ im gestörten Bereich [107, S. 460]. Dadurch rückt der Betriebspunkt der Schaufeln im gestörten Gebiet auf der Drehzahlkonstanten des Verdichterkennfeldes näher an die Pumpgrenze des Gesamtverdichters [11, S. 269-270], [62, S. w6], [65, S. 278-279], vgl. Abbildung 2.15. 


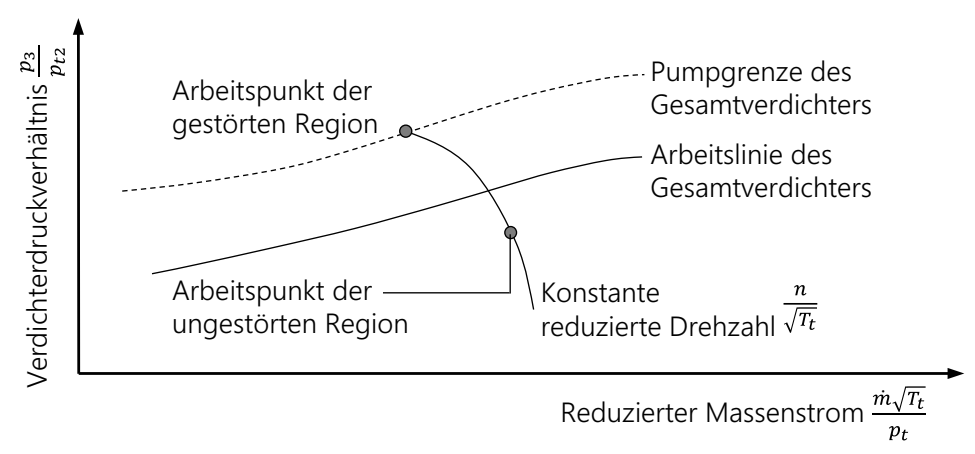

Abbildung 2.15 Ungleichförmigkeitseinfluss auf das Verdichterkennfeld

Überschreitet der Arbeitspunkt der gestörten Region die Pumpgrenze des Gesamtverdichters können Strömungsablösungen auftreten [107, S. 461]. Umfassen diese Strömungsablösungen einen größeren Sektor des Fans, kann die Fanströmung abreißen [11, S. 269-270], [103, S. 378]. Dadurch kann sich die Strömungsrichtung umkehren, was als Verdichterpumpen bekannt ist [11, S. 269270]. Daher muss die Pumpgrenze des Verdichters einen Spielraum bezüglich der Ungleichförmigkeit der Anströmung beinhalten [11, S. 269-270].

Der Einfluss einer Ungleichförmigkeit kann durch verschiedene Ungleichförmigkeitskoeffizienten/-korrelationen (Distortion Coefficients/Correlations, DCs) quantifiziert werden, beispielsweise $D C(60), D C(90)$, $D C$ (120), $K_{A 2}, K_{D}$ oder $K_{\text {rad }}$ [11, S. 270-272], [103, S. 380], [108]. Der häufig verwendete $D C(60)$-Wert beschreibt den Einfluss einer Ungleichförmigkeit in einem $60^{\circ}$-Sektor. Bei einem Umfangswinkel von mindestens $60^{\circ}$ erreicht eine Ungleichförmigkeit ein signifikantes Ausmaß [11, S. 270-272], [103]. Zur Ermittlung des $D C(60)$-Koeffizienten sind die Druckwerte in der Fanebene erforderlich. Diese werden mit einer sechsarmigen Sonde nach ARP $1420 \mathrm{C}$ [105], [109], [110], [111] aufgenommen. Der DC(60)-Koeffizient wird aus dem mittleren Totaldruck $p_{t 2, a v g}$, dem mittleren Totaldruck des Sektors mit minimalen Wert $p_{t 2, a v g 60^{\circ}, \min }$ und dem mittleren kinematischen Druck $q_{2, \text { avg }}$ bestimmt [11, S. 271], [103, S. 380]:

$$
D C(60)=\frac{p_{t 2, a v g}-p_{t 2, a v g 60^{\circ}, \min }}{q_{2, a v g}} .
$$


Ein $D C(60)$-Koeffizient von 0,5 wird typischerweise gefordert, jedoch können die meisten Verdichter Werte bis 1,0 tolerieren [103, S. 380].

\section{Luftwiderstand}

Der Schub $F_{n, \text { inst }}$, der vom installierten Triebwerk auf das Flugzeug übertragen wird, ergibt sich aus dem vom Triebwerk erzeugten Bruttoschub (Gross Thrust) $F_{\text {gross }}$ vermindert um alle negativ beitragenden Widerstands- und Verlustkräfte [10, S. 947-958], [11], [47, S. 125-128], [62], vgl. Abbildung 2.16. Auch sind für eine bessere Vergleichbarkeit unterschiedlicher Flugzeugmuster entdimensionalisierte Angaben dieser Kräfte verbreitet [97, S. 36-37]. Diese normieren die besagten Kräfte bezüglich der Fläche der Tragflügel und des kinematischen Drucks [97, S. 36-37].

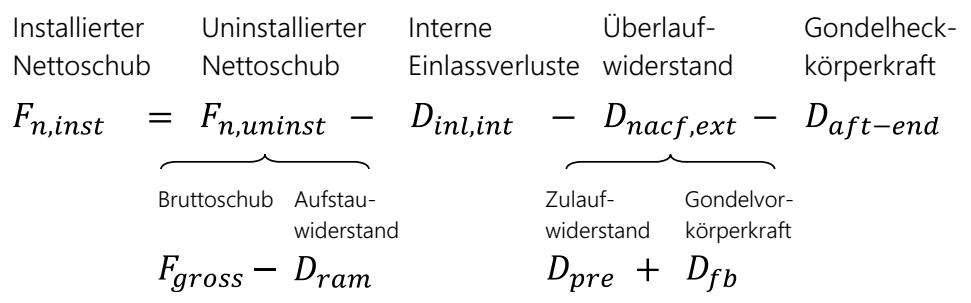

Abbildung 2.16 Zusammensetzung des installierten Nettoschubs

Die Differenz aus dem von den Triebwerken unter Vernachlässigung von Zapfluftmassenströmen erzeugten Bruttoschub

$$
F_{\text {gross }}=\left(\dot{m}_{0}+\dot{m}_{f u e l}\right) \cdot c_{9}+\left(p_{9}-p_{0}\right) \cdot A_{9},
$$

und dem Aufstauwiderstand (Ram Drag), der aus der Verzögerung der Luft beim Eintritt in den Einlass entsteht [97, S. 38],

$$
D_{\text {ram }}=\dot{m}_{0} \cdot c_{0}
$$

ergibt den uninstallierten Nettoschub $F_{n \text {,uninst }}$ als Funktion des Triebwerksluftmassenstroms $\dot{m}_{0}$, des Brennstoffmassenstroms $\dot{m}_{f u e l}$, der Düsenaustrittsgeschwindigkeit $c_{9}$, des Düsenaustrittsdruckes $p_{9}$, der Düsenaustrittsfläche $A_{9}$, des Umgebungsdrucks $p_{0}$ und der Fluggeschwindigkeit $c_{0}$ [47, S. 126-128]. 
Die Installation des Triebwerks in die Gondel bestimmt die verbleibenden Widerstandskomponenten, namentlich

- den Widerstand, der aus dem Einlassdruckverlust (Internal Inlet Losses) resultiert, $D_{i n l, i n t}$,

- den externen Gondelvorkörperwiderstand (External Nacelle Front Drag) $D_{\text {nacf,ext }}$, auch Überlaufwiderstand (Spillage Drag) genannt, und

- der Gondelheckkörperkraft (Aft-End Drag, Aft-Body Drag) Daft-end [10, S. 955-956], [47, S. 125].

Der aus dem Einlassdruckverlust $\pi_{i n l}$ resultierende Widerstand $D_{\text {inl,int }}$ hängt hauptsächlich vom Totaldruckverlust im Einlass und somit von der Gestaltung des Einlasses ab. Der externe Gondelvorkörperwiderstand $D_{\text {nacf, ext }}$ oder Überlaufwiderstand wird ebenfalls hauptsächlich durch die Geometrie des Einlasses bestimmt. Dieser Widerstand resultiert aus dem Zulaufwiderstand (Additive Drag, Pre-Entry Drag) $D_{\text {pre }}$ und der Gondelvorkörperkraft (Cowl Forebody Drag) $D_{f b}$ [10, S. 942], [47, S. 347], vgl. Abbildung 2.17.

Schnittansicht Gondelvorkörper

Querschnitt am maximalen Gondeldurchmesser $A_{\max }$

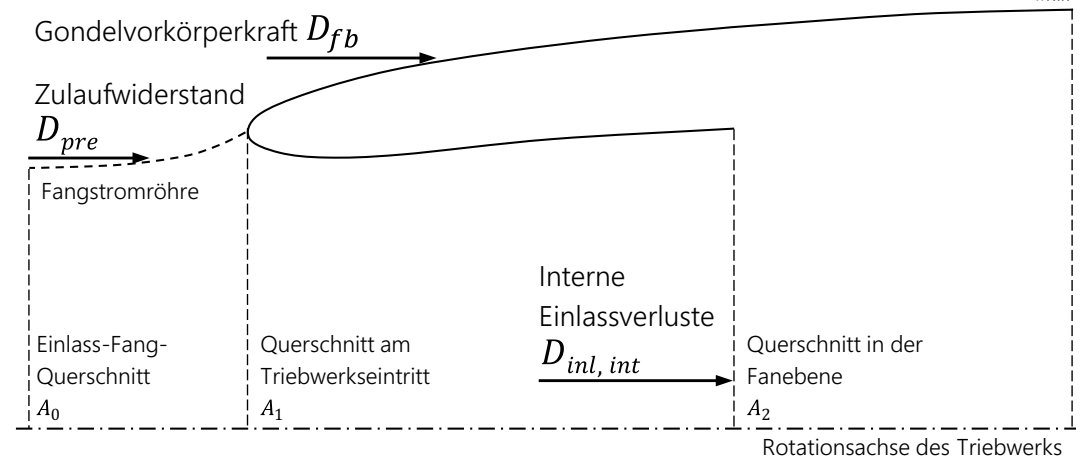

Abbildung 2.17 Zusammensetzung des Einlasswiderstands

Der Einlass umfasst die äußere Gondeloberfläche zwischen der Ebene des Triebwerkeintrittsquerschnitts $A_{1}$ und der Fanebene $A_{2}$. Somit beschreibt er nur einen Anteil des Gondelvorkörpers, der sich von der Einlassvorderkante bis zur Ebene des maximalen Gondelquerschnitts $A_{\max }$ erstreckt. Dennoch hängt der 
externe Gondelvorkörperwiderstand vorrangig von der Einlasskontur ab. Änderungen der Einlasskontur haben einen großen Einfluss auf die Druckverteilung auf dem gesamten Vorkörper. Deshalb sollte bei der Untersuchung des Einlasswiderstands der gesamte Gondelvorkörper in Betracht gezogen werden [11, S. 194-195]. Im Idealfall sollte der Einfluss des Einlasses auf das gesamte Flugzeug untersucht werden, um mögliche Interaktionen mit dem Flugzeugrumpf oder den Tragflächen abschätzen zu können.

Der Zulaufwiderstand $D_{\text {pre }}$ ist eine Kraft, die durch das Integral der Differenz zwischen dem statischen Druck auf der Fangstromröhre $p_{\text {ext }}$ und dem Umgebungsdruck $p_{0}$ ermittelt wird. Für divergierende Fangstromröhren mit $A_{0} / A_{1}<1$ resultiert dabei eine Widerstandskraft, bei konvergierenden, $A_{0} / A_{1}>1$, ergibt sich eine Saugkraft. Die Fachliteratur [10, S. 195], [11, S. 194], [47, S. 345-346], [62, S. w7], [71] stellt zahlreiche Definitionen dieser Kraft bereit. Eine Variante ist die Impulsform als Funktion des Triebwerksmassenstroms $\dot{m}_{0}$, der Triebwerkseintrittsgeschwindigkeit $c_{1}$, der Fluggeschwindigkeit $c_{0}$, des Triebwerkseintrittsdrucks $p_{1}$, des Umgebungsdrucks $p_{0}$ und des Triebwerkseintrittsquerschnitts $A_{1}$ [10, S. 951], [47, S. 345-346]:

$$
D_{\text {pre }}=\int_{A_{0}}^{A_{1}}\left(p_{\text {ext }}-p_{0}\right) d A=\dot{m}_{0}\left(c_{1}-c_{0}\right)+\left(p_{1}-p_{0}\right) A_{1} .
$$

Die Gondelvorkörperkraft $D_{f b}$ ist die Summe aus Druck- und Reibungswiderstand über dem Vorkörper zwischen dem Staupunkt auf der Einlasslippe $A_{1}$ und dem maximalen Gondeldurchmesser $A_{\max }$ [10, S. 947-950]:

$$
D_{f b}=\int_{A_{1}}^{A_{\max }}\left(p_{e x t}-p_{0}\right) d A+\int_{A_{1}}^{A_{\max }} \tau d A .
$$

Der erste Term dieser Gleichung repräsentiert den axialen Druckwiderstand, auch Profilwiderstand genannt. Der axiale Druckwiderstand ergibt sich aus der Differenz des in Strömungsrichtung projizierten statischen Drucks auf der äußeren Gondeloberfläche $p_{\text {ext }}$ und des statischen Umgebungsdrucks $p_{0}$. Der zweite Term beschreibt den Reibungswiderstand resultierend aus den viskosen Scherspannungen $\tau$ in der Grenzschicht des Gondelvorkörpers.

In Abhängigkeit der Wölbung der äußeren Einlasskontur kann der statische Druck auf dem Gondelvorkörper während des Unterschallreiseflugs unter das Druckniveau des Umgebungsdrucks gesenkt werden. In diesem Fall entsteht eine 
Saugkraft (Lip Suction Force, Cowl Thrust Force) [11, S. 194-196], [47, S. 125]. Im Überschallbetrieb ist der statische Oberflächendruck $p_{\text {ext }}$ aufgrund des Verdichtungsstoßes vor dem Einlass erhöht, weshalb keine Saugkraft erzeugt werden kann. Dieser zusätzliche Widerstand ist auch als Stoßwiderstand (Wave Drag) bekannt [74]. Der erhöhte Druck erfordert scharfe und dünne Geometrien, die weitere Verdichtungsstöße vermeiden und die projizierte Fläche des Vorkörpers minimieren.

Die Gondelheckkörperkraft $D_{\text {aft-end }}$ umfasst alle in der Düsenregion auftretende Widerstände (Base Drag, Boattail Drag) und wird in dieser Arbeit nicht detailliert betrachtet [47, S. 125].

\subsubsection{Schutz vor Vereisung}

Der Schutz des Flugzeugs und seiner Triebwerke vor Eisansammlungen und deren negativen Folgen stellt seit Beginn der Luftfahrt eine konstruktionstechnische Herausforderung dar. Deshalb wurden bereits in den 1930er bis 1940er Jahren erste Eisschutzsysteme (Ice Protection Systems, IPSs) untersucht und entwickelt [112], [113].

Potenziell nachteilige Auswirkungen der Vereisung sind eine verringerte Ablöseresistenz und ein erhöhter Luftwiderstand des Flugzeugs [114]. Dies kann zu einer Verringerung der Steigrate, der maximalen Fluggeschwindigkeit und der Antriebseffizienz sowie zu einem erhöhten Kraftstoffverbrauch und verlängerten Rollwegen führen [114]. Darüber hinaus können Vereisungen in ungenauen Sensor- und Sondendaten, z. B. für die Fluggeschwindigkeit, sowie in einer verschlechterten Flugzeugsteuerung resultieren [114]. Im Bereich des Einlasses kann Eisbildung zu Strömungsablösungen führen. Weiterhin kann Eis abplatzen und hinter dem Einlass liegende Komponenten, wie den Fan, beschädigen.

Die genannten Effekte können zu gefährlichen oder sogar katastrophalen Ereignissen führen [78]. Daher müssen Flugzeugkomponenten, wie

- die Windschutzscheiben im Cockpit,

- die Tragflächen und andere Auftriebsflächen,

- das Triebwerk, einschließlich des Einlasses und des Fans, sowie

- Messsysteme, z. B. die Druck- und Temperatursonden

vor Eisansammlungen geschützt werden [77, S. 762], [78], [113]. Für die luftfahrttechnische Zulassung eines IPS muss die Einhaltung der von der Europäischen Agentur für Flugsicherheit (EASA) in Bauvorschrift CS-25.1419 
(Certification Specification) [34] definierten Anforderungen bei maximaler Vereisungsgefahr nachgewiesen werden. Zudem müssen moderne Flugzeuge und ihre Komponenten einen bestimmten Grad an Vereisung sicher und ohne größere Leistungseinbußen tolerieren können [34]. Auf diese Weise kann im Falle einer Fehlfunktion des IPS für eine bestimmte Zeitspanne ein sicherer Flug gewährleistet werden. Weiterhin lässt sich dadurch der Energiebedarf des IPS, der z. B. durch das Zapfluftsystem oder die elektrischen Generatoren des Triebwerks gedeckt wird, minimieren.

\section{Vereisungsbedingungen}

Zahlreiche Studien [114], [115], [116], [117] befassen sich mit den Mechanismen der Eisbildung an Flugzeugen, die weiterhin nicht vollständig verstanden sind. Eisbildung am Flugzeug kann sowohl am Boden als auch während des Fluges auftreten [77, S. 763]. Am Boden gebildetes Eis wird durch Enteisungsfluide am jeweiligen Flughafen entfernt. Eis, das sich während des Fluges bildet, ist durch Technologien, die in das Flugzeug integriert werden, zu entfernen oder bereits in der Entstehung zu verhindern [77, S. 763].

In Wolken kann Wasser in Form unterkühlter Tröpfchen (Super-cooled Droplets) bis zu Temperaturen von $-40{ }^{\circ} \mathrm{C}$ im flüssigen Zustand verbleiben [77, S. 763], [114]. Um zu gefrieren, muss das Wasser seine verborgene innere Gefrierwärme (Latent Heat of Freezing) abgeben, um sich in Eis umzuwandeln. Diese Wärmeabgabe kann an die Umgebungsluft erfolgen, wodurch Eiskristalle entstehen, oder an eine Oberfläche, was zur Eisbildung auf dieser führt [77, S. 763], [118]. Während des Fluges in Wolken bei Temperaturen um oder unter dem Gefrierpunkt von $0{ }^{\circ} \mathrm{C}$ können unterkühlte Tröpfchen auf die Flugzeugoberfläche auftreffen, gefrieren und zu Eisansammlungen führen. Innerhalb des Einlasskanals des Flugtriebwerks kann Eis durch adiabatische Kühlung (Adiabatic Cooling) bei Temperaturen über dem Gefrierpunkt von bis zu $+5{ }^{\circ} \mathrm{C}$ entstehen [113]. Neben der Temperatur hängt die Menge des entstehenden Eises und die Entstehungsrate auf einer Oberfläche von der Form, Größe und Beschaffenheit der Oberfläche, der relativen Geschwindigkeit der Tröpfchen zur Oberfläche sowie der Konzentration von flüssigem Wasser und der Tröpfchengröße innerhalb der Wolke ab [113], [114]. Darüber hinaus ist die Wärmeübertragung zwischen der Oberfläche und dem Tröpfchen von Bedeutung. Diese ist abhängig von verschiedenen physikalischen Effekten, wie der aerodynamischen Erwärmung, der konvektiven Kühlung, der Verdunstungskühlung und der latenten Gefrierwärme [113], [114].

Die beiden Hauptformen der Vereisung sind Raueis (Rime Ice) und Klareis (Glaze Ice) [113], vgl. Abbildung 2.18. Raueis entsteht, wenn die Tröpfchen 
beim Aufprall auf die Oberfläche vollständig gefrieren. Dies führt zu Lufteinschlüssen, durch die eine milchige, undurchsichtige Struktur entsteht [77, S. 764]. Meistens sind Raueisansammlungen stromlinienförmig und spröde, weisen aber eine große Oberflächenrauheit auf [77, S. 764]. Durch das Anwachsen von Raueisansammlungen können sich Hörner bilden, die über deutlich schlechtere Strömungseigenschaften verfügen [113].
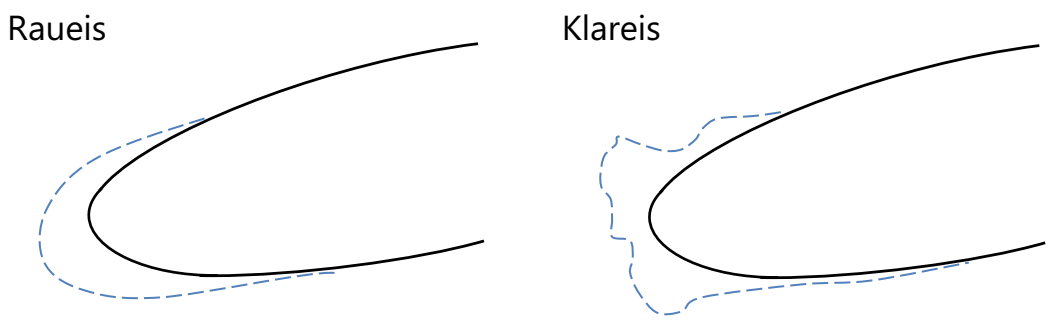

Abbildung 2.18 Eisansammlungsformen auf aerodynamischen Profilen

Das transparente, durchscheinende Klareis stellt die kritischere Form der Vereisung dar. Es kann sich bilden, wenn beim Aufprall auf die Oberfläche nur ein Teil des auftreffenden Wassers sofort gefriert [114]. Dies ist bei Kombinationen von warmen Temperaturen, großen Geschwindigkeiten oder hohen Wasserkonzentrationen in Wolken möglich [114]. Das verbleibende flüssige Wasser kann entlang der Oberfläche in hintere Regionen fließen, gefrieren und lokale Verdickungen bis hin zu Hörnern bilden [114]. Die Oberfläche von Klareis hat eine geringe Rauheit, kann jedoch Risse von bis zu einem Millimeter und Knötchen von mehreren Millimetern Höhe bilden [101]. Weiterhin existieren Mischformen von Raueis und Klareis, die die negativen Eigenschaften beider Hauptformen in sich vereinen [77, S. 764].

\section{Eisdetektion}

Die Erkennung des Beginns von Vereisungsbedingungen ist wichtig, um deren gefährliche Auswirkungen zu verhindern und um Energieverschwendung durch ein permanent aktives IPS zu umgehen. Früher mussten die Piloten Eisbildung auf den Cockpit-Scheiben und Wischerblättern erkennen. Heutzutage existieren Eisdetektoren, um die Arbeitsbelastung der Piloten zu reduzieren und die Zuverlässigkeit der Eiserkennung bei Nachtflügen zu erhöhen [113]. Eisdetektoren informieren die Besatzung über das Vorhandensein von Vereisungsbedingungen 
und/oder aktivieren das IPS [113]. Darüber hinaus erkennen sie den Austritt aus Vereisungsbedingungen, wodurch der Energieverbrauch durch rechtzeitige Abschaltung des IPS reduziert werden kann.

Eisdetektionssysteme für Flugzeuge können als

- beratende Eisdetektionssysteme,

- primär manuelle Eisdetektionssysteme und

- primär automatische Eisdetektionssysteme

ausgeführt werden [119]. Beratende Eisdetektionssysteme dienen als Absicherung für die Erkennung von Vereisungsbedingungen, die von der Flugbesatzung basierend auf Temperaturdaten und sichtbarer Feuchtigkeit erkannt werden müssen. Primär manuelle Systeme informieren die Besatzung über die aktuellen Vereisungsbedingungen, wobei die Aktivierung des IPS der Besatzung überlassen bleibt. Im Gegensatz dazu erkennen primär automatische Systeme Vereisungsbedingungen, aktivieren das IPS und informieren die Besatzung über beides.

Eisdetektionssysteme können auf thermischen, optischen und mechanischen Prinzipien basieren [119]. Thermische Systeme zeigen das Vorhandensein von Eis an, indem sie z. B. eine Änderung des Temperaturgradienten einer beheizten Oberfläche messen. Diese Änderung kann durch die Schmelzwärme von potenziell angesammeltem Eis, das auf der beheizten Oberfläche schmilzt, entstehen [113]. Diese Systeme werden bislang noch nicht serienmäßig eingesetzt. Optische Detektionssysteme von Penny \& Giles [120] nutzen Lichtstrahlen zum Erfassen der Wachstumsgeschwindigkeit des Eises [119]. Anwendung finden sie bei Rotorflüglern, wie dem Agusta Westland AW101 und dem Sikorsky S92. Ältere militärische Transportflugzeuge nutzen mechanische Eisdetektoren mit einem rotierenden Zylinder von Lucas Aerospace [113], [121]. Hierbei wird ein kleiner Zylinder an einem Abstreifblech entlang rotiert und das zum Abstreifen erforderliche Drehmoment gemessen. Bei der Bildung von Eis erhöht sich das Drehmoment und Eisbildung wird erkannt.

Die meisten Verkehrsflugzeuge verwenden elektromechanische Eisdetektoren von UTC Aerospace Systems [122]. Diese Eisdetektorbauart regt eine Sonde im Luftstrom zu Schwingungen mit einer konstanten Frequenz von etwa $40 \mathrm{kHz}$ an [77, S. 769], [113]. Sobald sich Eis an der Sonde ansammelt, erhöht sich die schwingende Masse, wodurch die Frequenz reduziert wird. Unterschreitet die Frequenz einen Schwellenwert, wird Vereisung signalisiert [113]. Durch Aufheizen der Sonde wird diese vom Eis befreit und der Vorgang kann wiederholt werden [77, S. 769]. 


\section{Eisschutzsystemarten}

Die von Eisansammlungen ausgehende Gefahr kann durch Eisverhütung (AntiIcing) oder Enteisung (De-Icing) vermieden werden [77, S. 763]. Eisverhütung beschreibt die Vorbeugung von Eisansammlungen, während Enteisung die zyklische Entfernung kleiner Eisansammlungen von einer Oberfläche beschreibt [77, S. 763]. Jedes Eisverhütungssystem kann auch als Enteisungssystem fungieren, um somit den erforderlichen Energieverbrauch zu reduzieren. Jedoch gewährleistet der Eisverhütungsbetrieb die aerodynamisch beste Oberfläche. Darüber hinaus können Eisverhütungssysteme im Verdampfungsbetrieb oder im Nassfließbetrieb arbeiten [113]. Vollständig verdampfende Systeme entfernen alle Spuren von Wasser von einer Oberfläche durch Erwärmung. Diese Methode erfordert sehr hohe Energiemengen. Systeme im Nassfließbetrieb verhindern eine Eisablagerung, indem sie die Oberfläche nur über den Gefrierpunkt des Wassers erhitzen, wodurch viel weniger Energie benötigt wird. Aus Sicherheitsgründen muss jedoch berücksichtigt werden, dass weiterfließendes Wasser stromabwärts der beheizten Oberfläche erneut eine Eisablagerung bilden kann, sogenanntes Runback-Eis [77, S. 767], [113].

Enteisungssysteme werden häufig auf Oberflächen eingesetzt, die einen gewissen Eisansatz tolerieren können oder bei bauartbedingt nur stark eingeschränkt zur Verfügung stehender Energie. Im Gegensatz dazu werden Eisverhütungssysteme in der Regel in Bereichen eingesetzt, die anfällig für eine gestörte Aerodynamik sind oder in denen abplatzendes Eis gefährliche Schäden verursachen kann.

Der Energiebedarf von IPSs wird beispielsweise auf Tragflächen durch die Kombination von Verdampfungsbetrieb und Nassfließbetrieb optimiert [113]. Während für die aerodynamisch empfindlichere Oberseite ein verdampfendes System verwendet wird, wird auf der Unterseite ein nasslaufendes System eingesetzt, welches die Bildung von aerodynamisch tolerierbarem Runback-Eis stromab der beheizten Fläche ermöglicht [113].

In der Luftfahrt fanden bisher pneumatisch, elektrisch oder chemisch betriebene IPSs Anwendung [113], vgl. Abbildung 2.19.

Pneumatische IPSs können heiße Zapfluft (Bleed Air) aus dem Verdichter des Triebwerks zum Vereisungsschutz nutzen oder Druckluft verwenden, um Gummimatten aufzupumpen und somit das Eis abplatzen zu lassen. Enteisungsflüssigkeiten setzen den Gefrierpunkt von Wasser herab und lösen somit Eis auf. Elektrische IPSs können auf elektrothermischen, elektromechanischen oder hybriden Prinzipen basieren. Während elektrothermische IPSs Heizelemente zum Aufheizen der Oberfläche nutzen, regen elektromechanische IPSs die Außenhülle zum Schwingen an, wodurch angesammeltes Eis abplatzt. 


\section{Abbildung 2.19}

Wirkprinzipe von

Eisschutzsystemen
Wirkprinzip

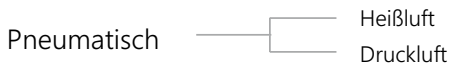

Chemisch

Enteisungsflüssigkeit

Elektromechanisch

Elektrothermisch

Darüber hinaus existieren zahlreiche innovative Eisschutzsysteme, die noch nicht Einzug in den Serienbetrieb hielten. Dazu zählen beispielsweise

- eisabweisende Beschichtungen [123], [124], [125],

- Ultraschallwellen,

- Mikrowellen,

- Elektrolyse,

- Formgedächtnislegierungen (Shape Memory Alloys, SMAs),

- Piezoelektrika sowie

- Hybridsysteme elektrothermischer und elektromechanischer IPSs [77, S. 762], [112], [113], [126].

\section{Heißlufteisschutzsysteme}

Viele Jahre waren Heißluft-IPSs aufgrund der guten Verfügbarkeit heißer Triebwerkszapfluft die bevorzugten Systeme für den Eisschutz der Tragflächen und des Leitwerks von Verkehrsflugzeugen [77, S. 769], [127]. Jedoch sind für diese großen Flächen signifikante Mengen Zapfluft erforderlich und somit Leistungsverluste sowie zusätzlicher Installations- und Wartungsaufwand einhergehend [127]. Auch deshalb wurden in jüngerer Vergangenheit zunehmend elektrische Systeme in Flugzeugen (More-Electric Aircraft) verwendet, beispielweise beim Vereisungsschutz der Tragflächen der Boeing 787 [112], [127]. Aufgrund ihrer Nähe zum Triebwerk werden Heißluft-IPSs weiterhin vorranging im Einlass von Strahltriebwerken eingesetzt [113]. Bei Triebwerksarten mit geringeren Mengen an verfügbarer Zapfluft, wie Turboproptriebwerken, oder bei komplexeren Einlassformen, wie dreidimensional geformten Einlasskanälen (S-Ducts), werden elektrothermische Systeme bevorzugt [113]. 
Heißluft-IPSs werden vorrangig im Eisverhütungsbetrieb eingesetzt [113]. Eine Ausnahme stellen die Tragflächen der Lockheed C130-Hercules dar, die mittels zyklischem Enteisungsbetrieb geschützt werden [113].

In Heißluft-IPSs wird Verdichterzapfluft mit einer Temperatur von $200{ }^{\circ} \mathrm{C}$ [114] bis $260{ }^{\circ} \mathrm{C}$ [57], [127] durch isolierte Rohre und Ventile zum sogenannten Piccolo-Rohr in der Flügel- oder der Einlassvorderkante geleitet [77, S. 770], vgl. Abbildung 2.20 links. Das Piccolo-Rohr verläuft innenliegend entlang der gesamten Vorderkante. Es ist mit Löchern versehen, um eine gleichmäßige Verteilung der Zapfluft innerhalb der Vorderkante zu gewährleisten und somit den erforderlichen Zapfluftmassenstrom zu minimieren [113]. Zur Maximierung des Wärmeübergangs besteht die Vorderkante im Allgemeinen aus Aluminium [113]. Weiterhin werden Schottwände eingesetzt, um naheliegende Komponenten vor den hohen Temperaturen zu schützen und um die Abluft durch die Abluftbohrungen auszuleiten [113].

\section{Heißlufteisschutzsystem}



\section{Drucklufteisschutzsystem}

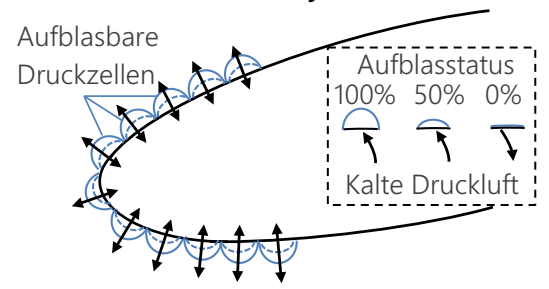

Abbildung 2.20 Gestaltung pneumatischer Eisschutzsysteme

Bewegliche Strukturen, wie z. B. die Vorflügel (Slats), können durch den Einsatz von Teleskoprohren und flexiblen Kupplungen mit Zapfluft versorgt werden [77, S. 770], [75]. Weiterhin können Druck- und Temperatursensoren, ein Überhitzungsschutz und Druckbegrenzungs-, sowie Absperrventile erforderlich sein, um Systemfehler zu erkennen und zu behandeln [113]. Darüber hinaus stellt die Bestimmung und Regelung des erforderlichen und des verfügbaren Zapfluftmassenstroms sowie seiner Temperatur ohne negative Beeinflussung der Flugeigenschaften eine Herausforderung dar [113].

\section{Drucklufteisschutzsysteme}

Druckluft-IPSs werden typischerweise in Form pneumatischer Enteisungsmatten auf den Tragflächen von Turboprop-Flugzeugen eingesetzt [78]. Sie können nur 
als Enteisungssysteme betrieben werden. Enteisungsmatten bestehen aus aufblasbaren Druckzellen. Dies sind zumeist synthetische Gummibälge oder -schläuche (Pneumatic Boots), die entweder parallel oder senkrecht (Abbildung 2.20 rechts) zur Strömungsrichtung angeordnet sind [77, S. 766], [78]. Die Installation der etwa zwei Millimeter dicken Matten erfolgt vorrangig im Bereich der Vorderkante, wo das höchste Potenzial für die Eisbildung besteht [77, S. 766], [113].

Das Druckluft-IPS erlaubt Eisdicken von etwa $0,6 \mathrm{~cm}$ bis $1,3 \mathrm{~cm}$ bevor Luft in die Schläuche gepumpt wird, um diese aufzublasen [113]. Dieser Prozess kann automatisch oder durch die Besatzung eingeleitet werden und ist nach einer Zeitspanne von fünf bis sechs Sekunden abgeschlossen [77, S. 766]. Durch die Ausdehnung der aufgeblasenen Schläuche bilden sich Risse im Eis und es platzt durch die wirkenden Strömungskräfte ab [113]. Anschließend muss die Luft wieder abgesaugt werden, um die strömungsmechanische Beeinflussung durch die Schläuche zu minimieren. Bei niedrigem Umgebungsdruck in großer Höhe muss zudem ein Unterdruck erzeugt werden, damit die Schläuche weiter auf der Flügeloberfläche aufliegen [113].

Das Zulassen einer gewissen Eisdicke lässt die Möglichkeit einer zu späten Aktivierung des IPS offen und riskiert somit größere Eisansammlungen, die zu Strömungsablösungen an den Tragflächen führen können. Diese können zum Verlust der Kontrolle über das Flugzeug und letztlich zum Verlust des Flugzeugs führen. Daher ordnet die Luftfahrtbehörde der Vereinigten Staaten von Amerika FAA für einige Flugzeugtypen mit Druckluft-IPS bei Detektion von Vereisungsbedingungen die sofortige Aktivierung des Systems an [113].

Druckluft-IPSs kombinieren eine akzeptable Masse mit einem relativ geringen Leistungsbedarf [113]. Allerdings sind die Gummischläuche normalerweise auf Neoprenbasis und somit erosionsanfällig, was zu einer begrenzten Lebensdauer führt [113]. Zusätzlich werden bei einigen Druckluft-IPSs Beschichtungen mit reduzierter Haftfestigkeit zur Verbesserung der Abwurffähigkeit eingesetzt [113]. Darüber hinaus gibt es Untersuchungen zu Druckluft-IPSs mit pulsierenden Aufblaszyklen und Fokus auf Minimierung des zusätzlichen Luftwiderstandes, der durch das Aufblasen der Schläuche entsteht [113], [128].

\section{Flüssigkeitseisschutzsysteme}

$\mathrm{Zu}$ Beginn der IPSs in den 1930er Jahren waren Flüssigkeits-IPSs weit verbreitet [113]. Auch heute werden sie noch in vielen kleinen und mittelgroßen Flugzeugen eingesetzt, z. B. in Flugzeugen der Marken Beech, Cessna, Cirrus, Diamond, Piper und Mooney [112], [113]. Das System wird nur von CAV Aerospace [129] 
hergestellt und ist für den Eisverhütungsbetrieb konzipiert, kann aber auch zur Enteisung von bestehenden Eisansammlungen eingesetzt werden [113].

Flüssigkeits-IPSs entfernen Eis mittels einer Enteisungsflüssigkeit auf Glykolbasis, z. B. TKS-Enteisungsfluid [130], welches den Gefrierpunkt von Wasser herabsetzt [112]. Die Enteisungsflüssigkeit wird in Tanks gelagert und über Leitungen in einen Verteilungskanal im zu enteisenden Bauteil, z. B. eine Flügelvorderkante, gepumpt. Die zu enteisende Oberfläche verfügt über mikroporöse Löcher, durch die die Flüssigkeit an die Oberfläche fließt, wo sie das angesammelte Eis aufschmilzt und weitere Eisbildung verhindert, vgl. Abbildung 2.21. Anschließend fließen die Enteisungsflüssigkeit und das geschmolzene Wasser durch die wirkenden Strömungskräfte stromabwärts entlang der Oberfläche. Dabei wird die Entstehung von Runback-Eis aufgrund des herabgesetzten Gefrierpunktes vermieden [113].

\section{Abbildung 2.21}

Gestaltung von Flüssig-

keitseisschutzsystemen

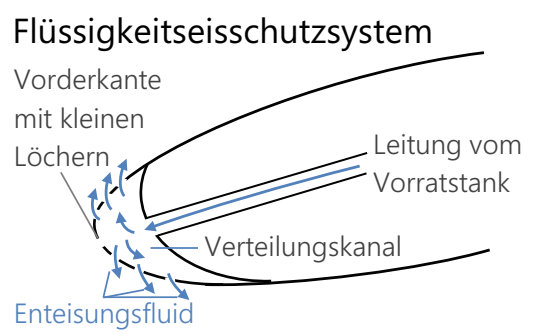

Vorteile des Flüssigkeits-IPS sind der geringe Bedarf an elektrischer Energie und die relativ geringe Masse der Versorgungsleitungen und des Vorratstanks [113]. Die Masse des Fluids ist jedoch der Haupttreiber für die Gesamtmasse des Systems, was bei Leichtflugzeugen zu einer typischen Masse des Systems von 45 bis $70 \mathrm{~kg}$ führt [113]. Der Hauptnachteil des Flüssigkeits-IPS besteht darin, dass es nur funktioniert, solange Enteisungsflüssigkeit vorhanden ist, wodurch eine Flüssigkeitsleckage oder ein zu kleines Reservoir zu gefährlichen Ereignissen führen können [113].

\section{Elektrothermische Eisschutzsysteme}

Elektrothermische IPSs sind die bevorzugte Wahl für den Eisschutz der Propeller von Turboprop-Triebwerken sowie für Rotorblätter von Hubschraubern [113]. Für diese Anwendungen werden elektrothermische Anwendungen gegenüber Heißluft-IPSs bevorzugt, da die Zuführung von Zapfluft in die rotierenden Blätter herausfordernd ist und die Temperatur der Zapfluft für die üblicherweise 
verwendeten Glas- und Kohlefasermaterialien moderner Rotorblätter zu hoch ist [113]. Elektrothermische IPSs werden bei Rotorblättern normalerweise im zyklischen Enteisungsbetrieb verwendet, da selten ausreichend elektrische Energie für einen Eisvermeidungsbetrieb zur Verfügung steht [77, S. 768], [113]. Selbst ein Hubschrauber mittlerer Größe erfordert allein für den Enteisungsbetrieb einige zehntausend Watt [113]. Aufgrund der Entwicklungstendenzen bei Triebwerken hin $\mathrm{zu}$ geringerem verfügbaren Zapfluftmassenstrom werden elektrothermische IPS jedoch zunehmend für die Anwendung in Betracht gezogen [113]. Die Anwendung des elektrothermischen IPS auf den Tragflächen der Boeing B787 erfordert etwa 100 bis $200 \mathrm{~kW}$ elektrische Leistung [79, S. 267], [113]. Darüber hinaus werden elektrothermische IPSs in Form dünner, transparenter Heizfolien für den Vereisungsschutz der Cockpitfrontscheibe und vorhandener Messsonden, wie der Staudrucksonde, verwendet [77, S. 769-770], [113].

Elektrothermische IPSs verwenden Widerstandsheizelemente zur Entfernung von Eis, vgl. Abbildung 2.22 links. Die Heizelemente können aus geätzten Folien, Drähten, Geweben, gespritztem Metall oder beschichteten Kohlefasern bestehen [113]. Die Heizelemente sind zudem beidseitig elektrisch isoliert. Darüber hinaus sind Leitungen für die Stromversorgung und die Steuerelektronik sowie Schutzmechanismen zur Vermeidung sehr hoher Temperaturen, wie z. B. Temperaturfühler, erforderlich. Eine Gesamtmasse des IPS von weniger als $20 \mathrm{~kg}$ kann durch den Einsatz von Heizelementen auf Grafitbasis erreicht werden, die von der NASA entwickelt wurden [112], [131]. Elektrothermische Systeme sind saubere und effiziente IPS-Lösungen mit einer langen Lebensdauer, die im hohen Maß von der Verlegung der Leitungen und deren Anschlüssen abhängt [113].

Elektrothermischer Schutz

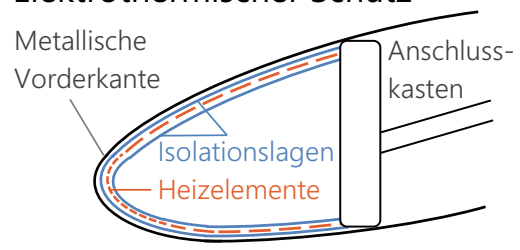

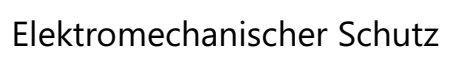

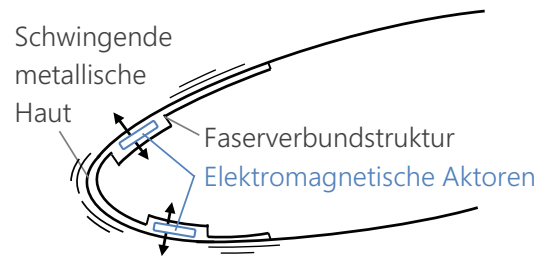

Abbildung 2.22 Gestaltung elektrischer Eisschutzsysteme 


\section{Elektromechanische Eisschutzsysteme}

Mögliche Lösungen für elektromechanische IPSs sind beispielsweise

- die Enteisung mittels interner elektromagnetischer Aktoren [132] (ElectroImpulse De-Icing, EIDI),

- die Enteisung mittels externer elektromagnetischer Aktoren [133] (ElectroExpulsive De-Icing, EEDI) und

- die Enteisung mittels externer elektromechanischer Aktoren [134] (ElectroMechanical Expulsion De-Icing, EMED) [112], [113], [135].

Die erstgenannte Bauart der EIDI-Systeme verwendet elektromagnetische Aktoren, die direkt unter der metallischen Außenhülle der zu schützenden Vorderkante angebracht sind. Die elektromagnetischen Aktoren sind überwiegend Drahtspulen, können aber auch als flache Metallstreifen ausgeführt werden [113]. Sobald die Spulen von einem Stromimpuls durchflossen werden, erzeugen sie einen entgegengesetzten Wirbelstrom in der Lippenhaut. Da die Spulen starr montiert sind, wird die Oberfläche mechanisch belastet und dadurch elastisch verformt, wodurch vorhandenes Eis abgeworfen wird [113]. Die mechanischen Belastungen, die Ermüdungseigenschaften der zu verformenden Struktur und die Positionierung der Aktoren erfordern während des Gestaltungsprozesses sorgfältige Aufmerksamkeit [113]. Darüber hinaus benötigt das IPS Komponenten zur Verteilung der elektrischen Leistung sowie große Kondensatoren [113]. Dieser IPS-Typ erfordert vergleichsweise wenig Energie. Bezüglich der Entstehung elektromagnetischer Interferenzen (EMI) divergieren die Einschätzungen [112], [113].

EEDI-Systeme finden Anwendung bei größeren unbemannten Fluggeräten (Unmanned Aerial Vehicle, UAVs), häufig auch als Drohnen bezeichnet [113]. Die elektromagnetischen Aktoren des EEDI-Systems sind auf der zu enteisenden Struktur aufgebracht und nur mit einem Elastomer überzogen. Bei der Aktivierung wird innerhalb einer Millisekunde eine Bewegung von etwa einem Mikrometer erzeugt, wodurch angelagertes Eis entfernt wird [112]. Der Hauptnachteil dieser Bauart ist die Anfälligkeit des Elastomers gegenüber Erosion und Beschädigungen durch Fremdkörper [112].

EMED-Systeme unterscheiden sich im Aufbau von EEDI-Systemen nur durch die Verwendung einer erosionsbeständigen Metalloberfläche an Stelle der Elastomerhaut [134], Abbildung 2.22 rechts. Der funktionale Unterschied besteht darin, dass beim EMED-System die Oberfläche nicht nur elastisch verformt wird, sondern hochfrequente Schwingungen angeregt werden, die angesammeltes Eis ablösen [112]. Dieser IPS-Typ zeichnet sich weiterhin durch einen sehr geringen Energiebedarf und eine geringe Masse aus [112]. 
Alle elektromechanischen IPSs haben einen geringen Leistungsbedarf, eine geringe Masse und entfernen den Großteil des Eises, das sich an der Vorderkante der betroffenen Struktur ansammelt. Jedoch hinterlassen sie häufig Resteis an den Seitenflanken, was zu aerodynamischen Verlusten führt [113].

\subsubsection{Reduktion von Schallemissionen}

Schall bezeichnet zeitliche Schwankungen von Dichte und Druck eines Mediums im Frequenzbereich von $16 \mathrm{~Hz}$ bis $16.000 \mathrm{~Hz}$ [10, S. 1485]. Diese Schwankungen breiten sich innerhalb des Mediums in Form von Schallwellen in einem Schallfeld aus. Für die Quantifizierung der Schwankungen wird der Schalldruck $p_{s}(t)$ verwendet. Dieser beschreibt die Differenz zwischen messbarem Gesamtdruck und dem statischen Umgebungsdruck $p_{0}$ [77, S. 213].

Das menschliche Gehör ist in der Lage, Schallwellen in der Luft mit einer Frequenz von ca. $1000 \mathrm{~Hz}$ ab einem Schalldruck von ca. $2 \cdot 10^{-5} \mathrm{~Pa}$ wahrzunehmen [10, S. 1485-1487], [77, S. 213]. Dabei wird die wahrgenommene Tonhöhe hauptsächlich von der Frequenz und die Lautstärke vorrangig vom effektiven Schalldruck $\tilde{p}_{s}$ bestimmt. Das Quadrat des effektiven Schalldrucks $\tilde{p}_{s}$ ist als zeitlicher Mittelwert des Schalldruckquadrats definiert [77, S. 213]:

$$
{\tilde{p_{s}}}^{2}=\overline{p_{s}(t)^{2}}
$$

Die Schmerzgrenze für die Lautstärke wird bei einem effektiven Schalldruck $\tilde{p}_{s}$ von etwa $2 \cdot 10^{1} \mathrm{~Pa}$ erreicht [10, S. 1487]. Dabei verläuft der wahrnehmbare Lautstärkeeindruck nicht linear, sondern annähernd logarithmisch. Deshalb und aufgrund des großen Wertebereichs werden in der Akustik logarithmische Pegelgrößen, wie der Schalldruckpegel $L_{p}$, verwendet [77, S. 213]:

$$
L_{p}=20 \lg \left(\tilde{p_{s}} / p_{\text {ref }}\right) d B, \quad p_{\text {ref }}=2 \cdot 10^{-5} P a
$$

Dadurch entspricht eine Verdopplung des Schalldrucks einer Erhöhung des Schalldruckpegels um etwa 6 dB [10, S. 1488]. Um den Einfluss von Messumgebung, -ort und -abstand auf das Schallfeld zu eliminieren, existiert zudem der Schallleistungspegel $L_{P}$ [10, S. 1488]:

$$
L_{P}=10 \lg \left(P / P_{\text {ref }}\right) d B, \quad P_{\text {ref }}=10^{-12} \mathrm{~W} .
$$


Die Schallleistung ist proportional zum Quadrat des effektiven Schalldrucks $\tilde{p}_{s}$ [10, S. 1488]. Eine Verdopplung der Schallleistung hat somit eine Erhöhung des Schallleistungspegels um etwa 3 dB zur Folge [10, S. 1488].

Als störend empfundene Schallereignisse werden als Lärm bezeichnet. Sowohl der Schalldruck als auch die Frequenz haben einen Einfluss auf die empfundene Störung. Um die Abhängigkeit des empfundenen Schalldruckpegels von der Frequenz zu umgehen, existieren sogenannte Schallbewertungskurven, die auf den gemessenen Schalldruckpegel $L_{p}$ aufaddiert werden [10, S. 1489]. In der Luftfahrt werden beispielsweise die A-Bewertung nach DIN-IEC 651 und die N-Bewertung der SAE verwendet [10, S. 1490], [77, S. 213].

Die empfundene Lästigkeit (Perceived Noise, PNdB) kann bei konstantem Schalldruckpegel, um bis zu $20 \mathrm{PNdB}$ variieren, was einer Vervierfachung der Lästigkeit in dieser Skala entspricht [100, S. 9]. Die empfundene Lästigkeit des Lärms hängt von Schallspitzen, Einzelgeräuschen und der Zeitdauer von Schallereignissen ab [10, S. 1491]. Diese Faktoren finden beim effektiv empfundenen Schallpegel (Effective Perceived Noise, EPNdB) Beachtung [77, S. 213]. Dieser wurde von der ICAO (Internationale Zivilluftfahrtorganisation, International Civil Aviation Organization) eigens für die Zertifizierung von Luftfahrzeugen entwickelt [10, S. 1491].

Um die Lästigkeit von Flugzeuglärm und dessen gesundheitsschädigende Wirkung für den Menschen [136] zu reduzieren, werden von Flughafenbetreibern [66, S. 58] und den Luftfahrtbehörden Grenzwerte für den erlaubten effektiv empfundenen Schallpegel festgelegt. In Europa werden diese von der EASA in der CS-36 [137] vorgeschrieben und verweisen auf ICAO Annex 16, Volume 1 [138]. Der maximal erlaubte Wert des effektiv empfundenen Schallpegels in Flughafennähe darf laut diesem, in Abhängigkeit von der Flugphase, der Flugzeugmasse und der Anzahl der Triebwerke im Bereich von 89 bis 106 EPNdB liegen [10, S. 1496]. Häufig verlangen Flughafenbetreiber für die Nutzung jedoch niedrigere Werte [66, S. 58].

\section{Lärmquellen}

Flugzeuglärm kann in aerodynamischen Lärm und Triebwerkslärm unterteilt werden. Aerodynamischer Lärm entsteht beispielsweise durch die Umströmung von Klappen oder bei Überlaufströmungen um den Gondelvorkörper [10, S. 1499]. Triebwerkslärm geht beispielsweise von Rotoren, wie dem Fan, und vom Abgasstrahl aus [10, S. 1499]. Zusätzlich kann Lärm durch Verdichtungsstöße entstehen [10, S. 1503]. Bis auf den Strahllärm, sind die genannten Lärmquellen für die Einlassgestaltung von Relevanz [100, S. 61]. 
Vorflügel mit Spalt verursachen aufgrund großer Turbulenzen besonders viel aerodynamischen Lärm über einem breiten Frequenzband [77, S. 221]. Dieser Lärm skaliert mit bis zu der fünften Potenz der Anströmgeschwindigkeit [77, S. 221]. Eine vergleichbare Wirkung haben Öffnungsklappen im Einlass, vgl. Abbildung 2.14. Fanlärm hat beim Flugzeugstart einen großen tonalen Anteil, dessen Frequenz von der Schaufelzahl und der Rotationsgeschwindigkeit abhängt [77, S. 218]. Hinzu kommen breitbandige Anteile aufgrund von Störungen der Fananströmung, Überschall-Machzahlen im Bereich der Schaufelspitzen (Buzz Saw Noise), Grenzschichtturbulenzen sowie Interaktionen der Nachlaufströmungen (Nachlaufdellen) zwischen Rotor und Stator [10, S. 1534], [66, S. 60-61], [77, S. 218]. Strahllärm ist breitbandig und primär von der Strahlgeschwindigkeit abhängig, was insbesondere im Überschall zu beachten ist [77, S. 218-220].

\section{Lärmreduktion}

Der vom Flugzeug abgestrahlte Lärm kann auf verschiedene Wege durch die Gestaltung des Einlasses reduziert werden. Beispiele hierfür sind:

- Abschirmung des Lärms vom Erdboden [9],

- gleichförmige Anströmung des Fans [10, S. 1534],

- angepasste Dimensionierung aerodynamischer Profile [77, S. 224],

- akustische Auskleidungen (Acoustic Liner) [10, S. 1540] und

- aktive Lärmminderungsmaßnahmen [77, S. 224].

Die bereits in Abbildung 2.13 dargestellten Einlässe mit negativem Schräganschnitt (Negative Scarfed Intakes), können den im Triebwerk entstehenden Schall nach oben ablenken [9], [99]. Ähnliche Abschirmeffekte können bei der Triebwerksmontage auf den Tragflächen oder dem Flugzeugrumpf von NurflügelKonstruktionen (Blended Wing Body) genutzt werden [7], [77, S. 42].

Störungen der Einlassströmung durch Fehlanströmungen, Querschnitte, die vom idealen Kreis abweichen, und Einbauten, wie Ringe, erzeugen am Fan Wechselwirkungen, die tonale Lärmeffekte zur Folge haben [10, S. 1534].

Die aerodynamische Dimensionierung von Profilen beinhaltet die möglichst schlanke Gestaltung von Strömungsprofilen, zu denen auch der Einlass zählt [77, S. 224]. Zusätzlich sollte eine geringe Profilnasenkrümmung umgesetzt werden, damit minimale lokale Beschleunigungen bei der Einlassumströmung auftreten [77, S. 224]. Folglich sind runde, dicke Einlasslippen für die Lärmminimierung zu bevorzugen [9]. Auf ausfahrbare Klappen und Öffnungen sollte aufgrund des erzeugten Lärms verzichtet werden [10, S. 1537], [100, S. 114], [139, S. 116]. 
Falls sie jedoch erforderlich sind, sollte eine lärmminimierende Klappenstellung identifiziert werden [77, S. 224].

Akustische Auskleidungen werden an verschiedenen Stellen des Triebwerks in den Wandungen des Strömungskanals in unterschiedlichen Bauformen eingesetzt [10, S. 1546]. Grundsätzlich verfügen alle bisher eingesetzten Bauformen über eine poröse Deckfläche mit darunterliegenden Wabenstrukturen, in denen sich Hohlräume ausbilden [10, S. 1543], [100, S. 143-144], vgl. Abbildung 2.23. Die Funktionsweise von akustischen Auskleidungen beruht vorrangig auf den Prinzipen der dissipativen Dämpfung und der reaktiven Auslöschung [10, S. 1543], [100, S. 143]. Dissipative Dämpfung beschreibt die Schwingungsanregung von Gasteilchen in den Poren des Deckmaterials [10, S. 1543]. Durch die Schwingung entsteht Reibung, die in einer Umwandlung der Schallenergie in Wärmeenergie resultiert [10, S. 1543]. Bei der reaktiven Auslöschung werden Schallwellen, die in die Hohlräume der Wabenstrukturen einfallen, am Boden der Struktur reflektiert [10, S. 1543]. Ist die Zelltiefe ein ungeradzahliges Vielfaches der eintretenden Wellenlänge, so wird die eintretende durch die reflektierte Schallwelle ausgelöscht und somit auch ein tonaler Anteil [10, S. 1543]. Das Material, die Größe der Poren und die Tiefe der Zellen werden in Abhängigkeit des Einsatzortes gewählt. Im Einlass finden als Deckschichtmaterial gewebte Glasfasermatten mit vergleichsweise hoher Porosität Anwendung [10, S. 1545-1546], [100, S. 147-148]. Diese erlauben die Dämpfung eines breiten Frequenzspektrums, auch unter Beachtung äußerer Einflüsse wie Schnee, Eis und Regen [10, S. 1545]. Als Material für den Wabenkern können beispielsweise Edelstahl oder Aluminium eingesetzt werden [10, S. 1546], [100, S. 147-148]. Um den tieffrequenten Kreissägenlärm des Fans zu dämpfen, sind diese Zellen meist einige Zentimeter tief [10, S. 1546]. Durch die Verwendung akustischer Auskleidungen im Einlass wird der Lärm um bis zu 5 PNdB verringert [100, S. 141]. Darüber hinaus existieren Konzepte bezüglich Auskleidungen aus Hartschaum [140] und Membranabsorbern [141]. Weiterhin werden Akustikauskleidungen im Bereich der Einlasslippe untersucht, wobei die Kompatibilität mit dem Eisschutzsystem zu gewährleisten ist [142].

$\mathrm{Zu}$ den aktiven Lärmminderungsmaßnahmen zählen die aktive Strömungsbeeinflussung durch Ausblasung, die Verstellung von Rotorblättern oder die Schallauslöschung durch Gegenschall [77, S. 225]. Das Prinzip des Gegenschalls könnte auch im Einlass Anwendung finden. Hierbei wird das Schallfeld über Mikrofone vermessen, analysiert und ein Gegenschallfeld erzeugt, das zur Auslöschung des gemessenen Schallfeldes führt [10, S. 1548], [143]. Das Gegenschallfeld kann dabei über Lautsprecher oder das Einblasen von Druckluft erzeugt werden [10, S. 1548-1549]. Weiterhin könnte die Fananströmung durch die Lufteinblasung positiv beeinflusst werden [10, S. 1550]. 


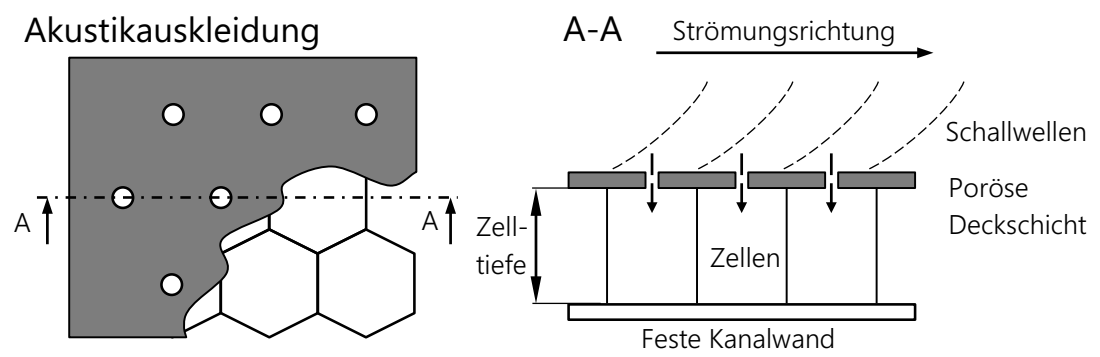

Dissipative Dämpfung

Teilchenschwingung

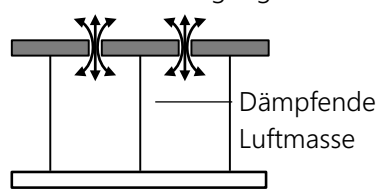

Reaktive Auslöschung

Eintretende Schallwelle

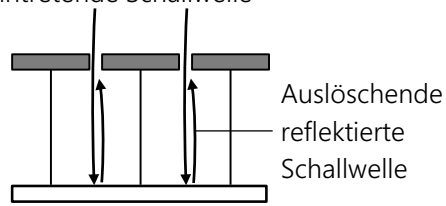

Abbildung 2.23 Aufbau von Akustikauskleidungen

\subsection{Variable Pitot-Einlässe}

Zur Erfüllung der aerodynamischen Anforderungen an den Einlass eines Triebwerks ist entweder ein Kompromiss oder eine variable Geometrie erforderlich, vgl. Abschnitt 2.2. Existierende Anwendungen für den reinen Unterschall- oder den Überschallbetrieb bis Mach 1,6 nutzen vorrangig starre Pitot-Einlässe, die eine Kompromisslösung darstellen. Einlässe für höhere Überschallgeschwindigkeiten verfügen überwiegend über andere Einlassbauweisen, die bewegliche Komponenten aufweisen, um den bestehenden Anforderungen gerecht zu werden [108]. Variable Pitot-Einlässe spielen in modernen Luftfahrtanwendungen nur eine untergeordnete Rolle, obwohl sie viele mögliche Vorteile aufweisen. Darüber hinaus existieren bereits zahlreiche Lösungsansätze für die Umsetzung variabler Pitot-Einlässe. Diese Lösungsansätze erfordern zum Teil den Einsatz neuartiger Technologien. 


\subsubsection{Mögliche Vorteile variabler Pitot-Einlässe}

Der Einsatz variabler Pitot-Einlässe bietet sowohl für reine Unterschall- als auch für Überschallanwendungen zahlreiche mögliche Vorteile hinsichtlich des Kraftstoffverbrauchs, der Reichweite, der Lärmemissionen und der Betriebssicherheit des Flugzeugs. Dem stehen potenzielle Nachteile bezüglich der Masse, der Zuverlässigkeit sowie der Entwicklungs-, Herstellungs- und Wartungskosten gegenüber.

\section{Vorteile variabler Pitot-Einlässe gegenüber starren Pitot-Einlässen}

Die Geometrie von Pitot-Einlässen kann in verschiedenen Abschnitten mit unterschiedlichen Effekten variiert werden. Möglichkeiten der Konturvariation des Einlasses bestehen in der Variation

- der Rundung der Einlasslippe,

- der Querschnittsflächen in Eintritts- und Kehlenebene,

- der Länge von Lippe, Diffusor und Gondelvorkörper und

- der Wölbung der Außenkontur des Gondelvorkörpers.

Eine Sonderform stellt die Grenzschichtbeeinflussung dar. Bei dieser verbleibt die geometrische Kontur des Einlasses unverändert, jedoch wird die umströmte Kontur, beispielsweise durch Lufteinblasung in die Grenzschicht, angepasst.

Während langsamer Flugphasen, wie dem Flugzeugstart, dem Durchstarten oder dem Steigflug, können große Anstellwinkel und starke Seitenwinde zu Strömungsablösungen und Ungleichförmigkeiten der Fananströmung mit allen damit verbundenen potenziellen Folgen führen. Durch einen variablen Einlass, der die Kontur ideal für diese Bedingungen anpasst, können diese Effekte minimiert werden. Eine Variation der Lippenkontur führt in diesen Phasen zu einer geringeren Beschleunigung der Strömung entlang der Einlasslippe hin zum engsten Querschnitt. Dadurch werden Turbulenzen, die Häufigkeit kompressibler Effekte und Strömungsablösungen reduziert. Dies wiederum verringert den erzeugten Lärm bei der Umströmung [77, S. 223], erhöht das Einlassdruckverhältnis und verbessert die Gleichförmigkeit der Fananströmung. Eine gleichförmigere Fananströmung resultiert in einem höheren Fanwirkungsgrad sowie verringertem Fanlärm. Eine Erhöhung der Wölbung der Außenkontur des Gondelvorkörpers im vorderen Bereich kann ebenso die Umströmung der Einlasslippe verbessern. Durch eine Verlängerung des Einlasses kann die Gleichförmigkeit der Anströmung des Fans positiv beeinflusst werden, da sich kleinere Störungen innerhalb 
des Strömungsfeldes ausgleichen können. Eine Vergrößerung der Eintrittsquerschnittsfläche $A_{1}$ resultiert in langsamen Phasen zudem in einer verbesserten Anpassung an die vorherrschenden Fangstromröhrenquerschnitte, vgl. Abbildung 2.5. Dadurch wird die erforderliche Umlenkung der Strömung, um die Einlasslippe reduziert, was ähnliche Effekte wie die Anpassung der Lippengeometrie hat. Zudem wird der Lärm der Einlassumströmung verringert [10, S. 1499]. Eine Erweiterung des Kehlenquerschnitts $A_{t h}$ hat verringerte Machzahlen im engsten Querschnitt zur Folge, wodurch lokale Überschallgeschwindigkeiten und resultierende kompressible Effekte vermieden werden können, was sich positiv auf das Einlassdruckverhältnis auswirkt.

Die Erhöhung der Ablöseresistenz und die verbesserte Gleichförmigkeit der Strömung vergrößern den Pumpgrenzabstand und verringern somit die Gefahr des Triebwerkspumpens [65, S. 278-279]. Der vergrößerte Pumpgrenzabstand kann genutzt werden, um die Beschleunigungsraten des Triebwerks zu erhöhen. In Kombination mit der verbesserten Ablöseresistenz, ermöglicht dies einen kürzeren Weg zum Starten sowie größere Anstellwinkel und Steigraten. Dies hat zur Folge, dass das Flugzeug weniger Lärm über eine kürzere Dauer in der Nähe des Flughafens erzeugt, was sich positiv auf die Zertifizierung des Flugzeugs und die Betriebskosten am Flughafen auswirken kann. Weiterhin könnte durch die verbesserte Ablöseresistenz die Sicherheit bei starkem Seitenwind erhöht werden. Dadurch könnten auch die Grenzwerte für Betrieb bei Seitenwind angepasst werden [34, 25.237]. Zudem könnte die Notwendigkeit des rollenden Starts einiger Flugzeuge vermieden werden, was kürzere Rollwege und Kraftstoffeinsparungen ermöglicht.

Für den Windmilling-Fall beim Ausfall eines Triebwerks könnte durch eine Verringerung der Eintrittsquerschnittsfläche $A_{1}$ der Überlaufwiderstand signifikant reduziert werden. Die verbleibenden Triebwerke müssten dadurch deutlich weniger Schub erzeugen als bei Verwendung starrer Einlässe. Dies könnte genutzt werden, um die sicherheitsbedingte Überdimensionierung von Triebwerken zu reduzieren.

Im Reiseflug ist der Einfluss von Seitenwinden aufgrund der vergleichsweise deutlich höheren Fluggeschwindigkeit annähernd vernachlässigbar. Auch sind übliche Anstellwinkel ziviler Anwendungen im Reiseflug deutlich kleiner, sodass vereinfacht von einer ungestörten axialen Einlassanströmung ausgegangen werden kann. Dadurch können aus aerodynamischer Sicht unterschiedliche Schnittgeometrien (Cross Sections), vgl. Abbildung 2.11, vermieden werden und die gesamte Geometrie vollständig für den Reiseflug optimiert werden. Darüber hinaus kann für den Unterschallreiseflug die Eintrittsquerschnittsfläche $A_{1}$ verkleinert werden, um besser an den Querschnitt der Fangstromröhre angepasst 
zu sein. Folglich wird der Überlauf der externen Strömung von der Einlasslippe zum äußeren Gondelvorkörper reduziert. Die Geometrie der äußeren Kontur des Gondelvorkörpers könnte zum Erzeugen einer maximalen Saugkraft auf diesem angepasst werden. Somit würde der resultierende Luftwiderstand des Flugzeuges positiv beeinflusst werden, wodurch die Schubanforderungen an die Triebwerke reduziert werden könnten. Eine Reduzierung des erforderlichen Schubs resultiert in einem verringerten Kraftstoffverbrauch. Infolgedessen könnte bei der gleichen mitgeführten Kraftstoffmenge eine größere Flugreichweite realisiert werden. Auch könnte die mitgeführte Kraftstoffmenge reduziert und somit die Nutzlast des Flugzeugs erhöht werden. Die Verringerung des Widerstands unterstützt zudem eine Erhöhung der Reisefluggeschwindigkeit im Unterschallbereich.

Für eine weitere Erhöhung der Geschwindigkeit in den Überschallbereich bis Mach 1,6 sollte eine weitere Anpassung der Geometrie erfolgen. Da aufgrund des senkrechten Verdichtungsstoßes vor dem Einlass keine Saugkraft auf dem Gondelvorkörper erzielt werden kann, gilt es, dessen Profilfläche zu minimieren und weitere Verdichtungsstöße auf der Außenkontur zu vermeiden. $\mathrm{Zu}$ beachten ist dabei, dass die Profilfläche des Einlasses auch vom maximalen Gondelquerschnitt abhängt. Dieser wiederrum wird auch durch Einbauteile, die gegenwärtig in der Triebwerksgondel unterzubringen sind, bestimmt und ist somit nur eingeschränkt variierbar. Weiterhin sollte die Lippengeometrie möglichst dünn bis scharf sein, wodurch sich die Einlasskehle in die Eintrittsebene verlagert [47, S. 359-360]. Hierbei ist die Fähigkeit der Verringerung der Lippenlänge vorteilhaft. Gleichzeitig ist ein längerer Diffusor vorteilhaft, um lokale Turbulenzen im Strömungsfeld nach dem vorausgehenden Verdichtungsstoß auszugleichen. Der Querschnitt der Eintrittsebene $A_{1}$ kann darüber hinaus an den vom Triebwerk geforderten Massenstrom angepasst werden, wodurch der Verdichtungsstoß möglichst nah an die Eintrittsebene heranrückt [47, S. 359-360]. Dadurch wird der erzeugte Überlaufwiderstand signifikant reduziert [47, S. 359-360]. Die Effekte einer Widerstandsreduktion sind für den Überschallbereich gleich denen im Unterschallbereich, jedoch ist das Potenzial im Überschallbereich deutlich größer.

Variable Pitot-Einlässe bieten eine erhöhte Sicherheit gegen Strömungsablösungen bei langsamen Flugzeuggeschwindigkeiten und eine Möglichkeit, den Betriebsbereich von Flugzeugen hin zu stärkerem Seitenwind zu erweitern. Zudem können sie erhöhte Steigraten unterstützen und somit den Lärm in Flughafennähe reduzieren. Gleichzeitig ermöglichen sie einen effizienteren Reiseflugbetrieb zukünftiger Überschallflugzeuge, sowohl im Unterschall über kontinentalem Gebiet als auch im Überschall über den Ozeanen. Darüber hinaus könnte die Variation der Einlassgeometrie als Enteisungsmechanismus verwendet 
werden. Weiterhin könnte eine Konturvariation durch Einblasung in die Grenzschicht neben positiven aerodynamischen Effekten eine Lärmreduktion nach sich ziehen.

\section{Vorteile variabler Pitot-Einlässe gegenüber anderen Bauformen}

Im Vergleich zu rechteckigen Einlässen mit externer Verdichtung haben PitotEinlässe bis Mach 1,6 zahlreiche Vorteile, die der eingeschränkten Druckrückgewinnung während des Überschallbetriebs gegenüberstehen. Als vorrangige Vorteile sind der geringe Luftwiderstand, das stabile Strömungsverhalten und die hohe Gleichförmigkeit der Fananströmung zu nennen [9], [11, S. 105]. Die höhere Gleichförmigkeit ermöglicht eine signifikant kürzere Länge des Einlasses und somit eine Reduzierung seines erforderlichen Bauraums und seiner Masse [9]. Zudem hat eine kürzere Länge einen positiven Einfluss auf die Dicke der sich bildenden Grenzschicht, wodurch zusätzliche Vorrichtungen zum Abscheiden der Grenzschicht vermieden werden können. Zum stabilen Strömungsverhalten zählt insbesondere, dass der Verdichtungsstoß aufgrund der scharfen Lippe und dem direkt anschließendem Diffusor in einer stabilen Lage befindlich ist [47, S. 359-360]. Bei Einlässen mit externer Verdichtung oder gemischter Verdichtung können hingegen starke Instabilitäten beim Übergang von Unterschall- zu Überschallbetrieb auftreten [47, S. 353-358], [108, S. 285-288]. Diese erfordern teils komplexe Start- und Kontroll-Einrichtungen, wie bewegliche Strömungskanalwandungen, offene Seitenflächen oder Nebenstromöffnungen [47, S. 371], [108, S. 289].

\subsubsection{Lösungsansätze variabler Geometrien}

Aufgrund der möglichen Vorteile im Vergleich zu einschränkenden starren Kompromisslösungen existieren zahlreiche Lösungsansätze für die variable Gestaltung von Tragflächenvorderkanten und Einlässen. Teilweise sind variable Pitot-Einlässe das primäre Anwendungsgebiet dieser Lösungsansätze. Größtenteils sind die Lösungsansätze jedoch für andere Anwendungen erarbeitet worden, weisen aber ein gewisses Anwendungspotenzial für variable Pitot-Einlässe auf.

Tabelle 2.1 gibt einen Überblick über existierende Patente bezüglich variabler Geometrien für Tragflächenvorderkanten und Einlässe. Zusätzlich ist angegeben, welche Parameter der Geometrie durch die jeweiligen Patente variiert werden können: 
- die Einlassquerschnittsfläche (A),

- die Vorderkantenrundung (R),

- die Profillänge (L) und/oder

- die Profildicke (T),

auf welcher Funktionsweise die Geometrievariation basiert:

- Verschieben/Rotieren fester Segmente einer geschlossenen Kontur (F),

- elastisches Verformen des Oberflächenmaterials (E),

- Bewegen von Vorkörpern/Klappen/Rampen/Konen (V) und/oder

- aerodynamisches Beeinflussen der Strömungsgrenzschicht (G),

für welche räumliche Dimension die Patente vorrangig geeignet sind:

- ebene (2D) oder

- ringförmige (3D) Anwendungen

sowie welche potenziellen Schwachstellen die jeweiligen Patente aufweisen:

- zu geringer Grad der Detaillierung der Lösungsidee (D)

- hohe Lärmemissionen, z. B. durch offene Klappen (L) oder

- große Komplexität der Lösung, funktionelle Schwachstellen, die zu einer verringerten Zuverlässigkeit des Systems führen können $(\mathbf{Z})$.

Es existieren zahlreiche Varianten der strukturierten Gruppierung von Patenten [219]. Nachfolgend erfolgt die primäre Unterteilung anhand der räumlichen Dimension der Anwendung und die anschließenden Unterteilungen entsprechend der zugehörigen Komponente und der Art der Variation, vgl. Abbildung 2.24.

Die Erzeugung variabler Geometrien, gestaltet sich in der Ebene deutlich einfacher als für ringförmige Strukturen im dreidimensionalen Raum. Deshalb existieren zahlreiche Anwendungen zweidimensionaler ebener Lösungen in Form variabler Tragflächenprofile und variabler rechteckiger Überschalleinlässe. Im dreidimensionalen Raum gibt es sowohl für den Zentralkörper als auch die ringförmige Einlasshülle insbesondere von Überschalleinlässen variable Lösungsansätze. Dabei kamen die meisten Lösungsansätze im Bereich der Einlasshülle nicht über den Status der Patentidee hinaus. 







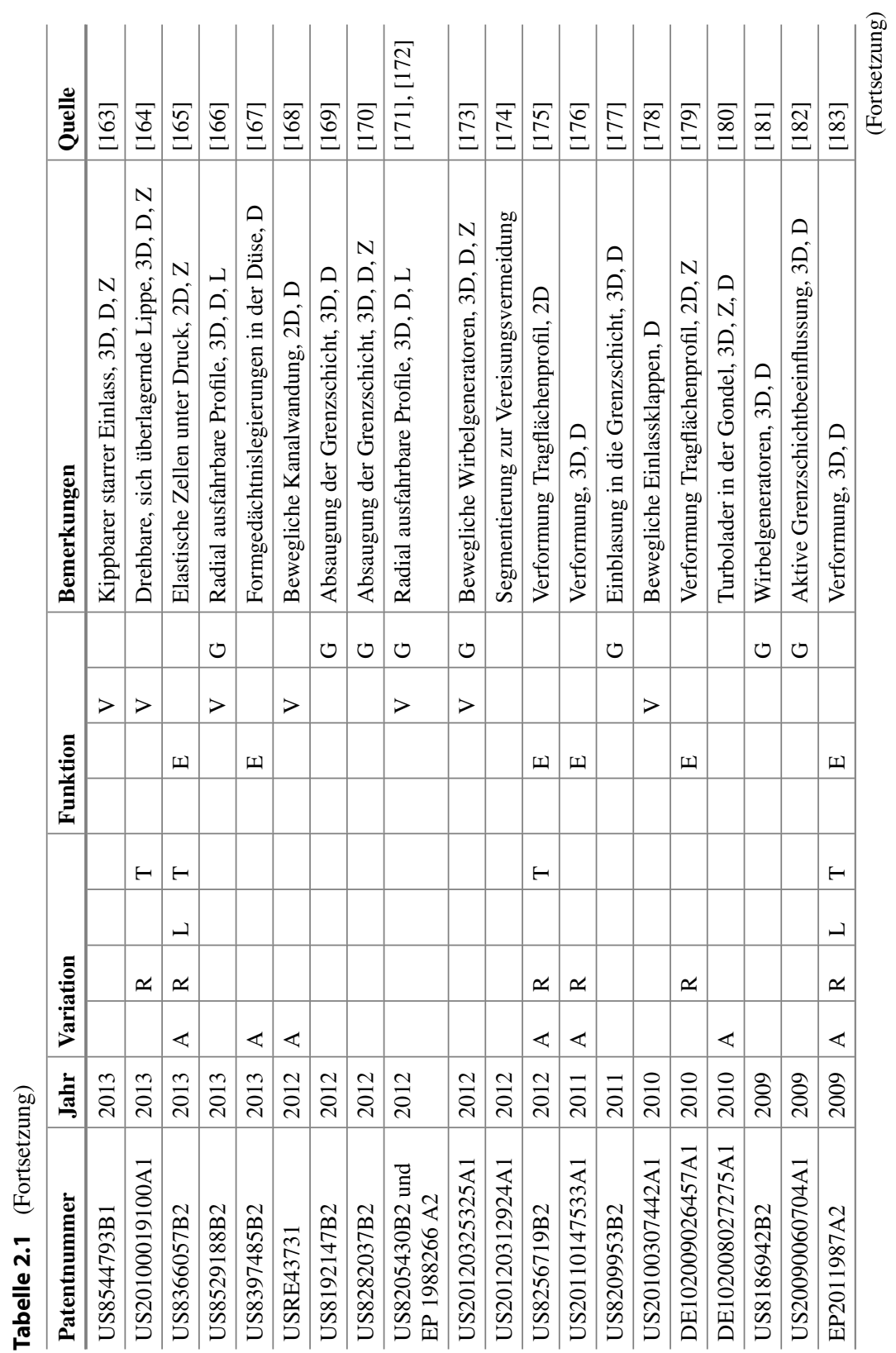






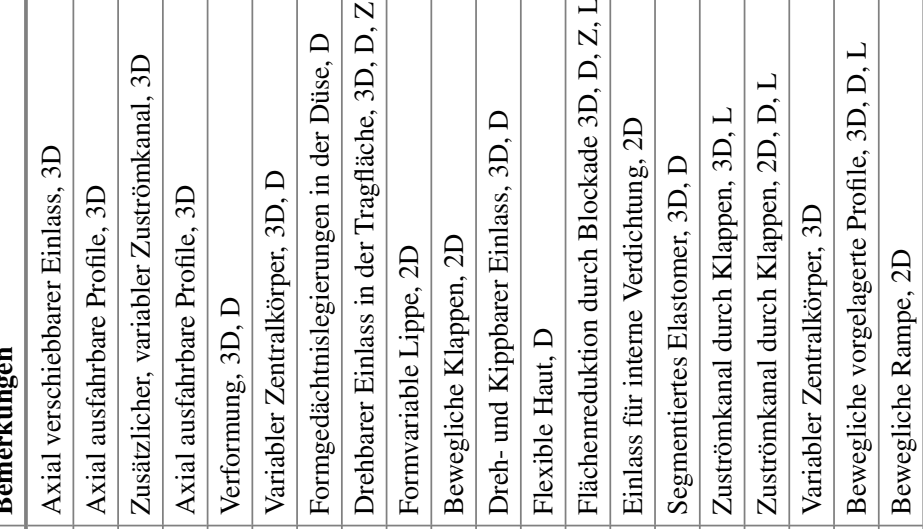

$\bullet$

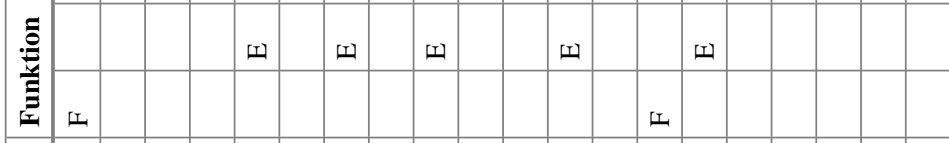

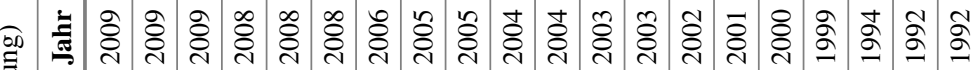

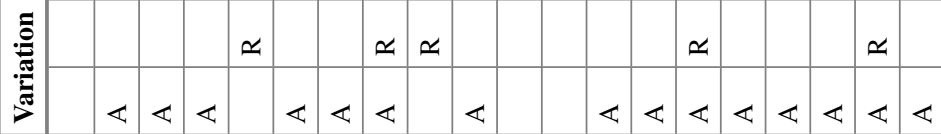






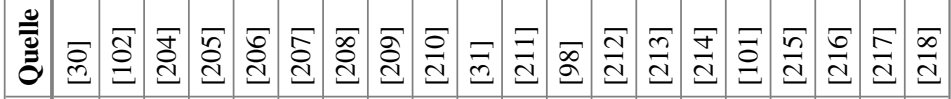

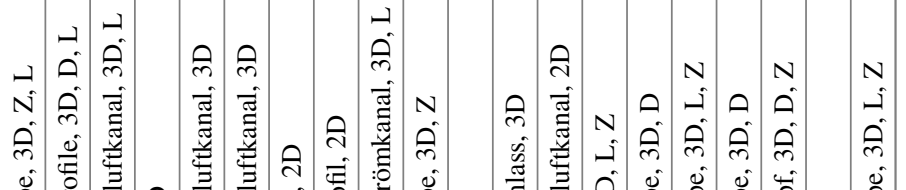

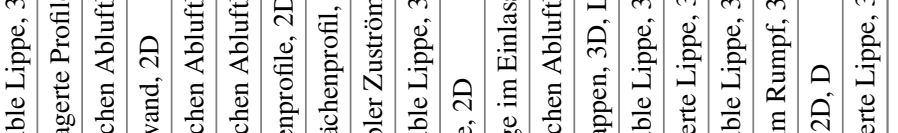

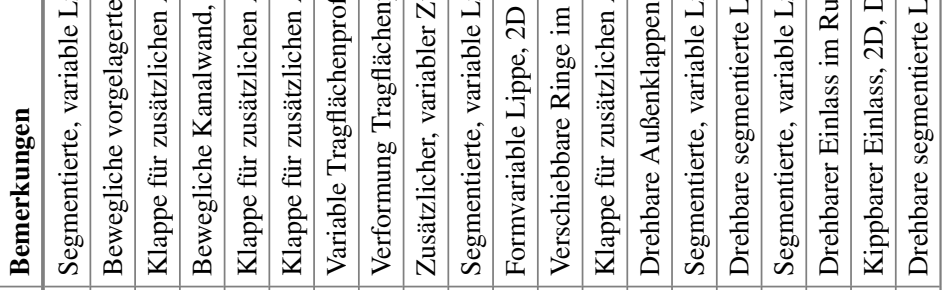

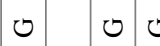

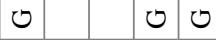

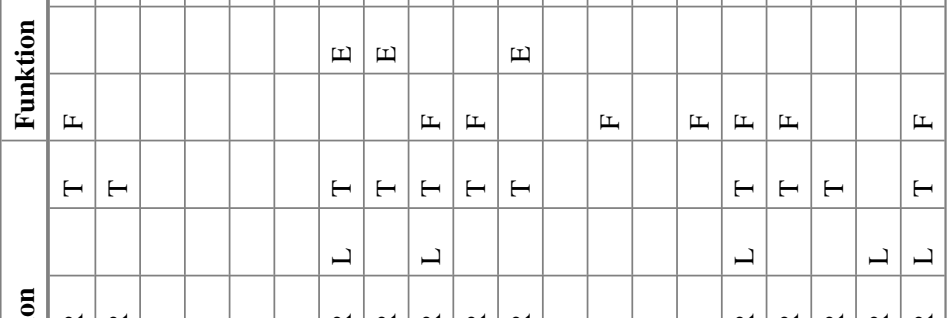

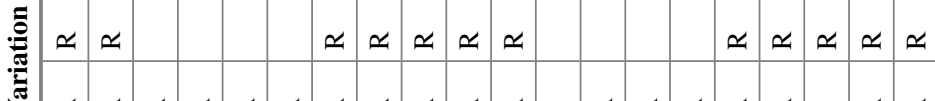

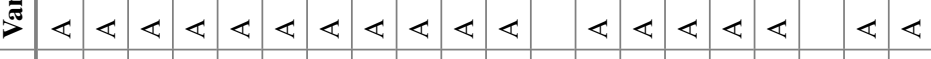

OD

过

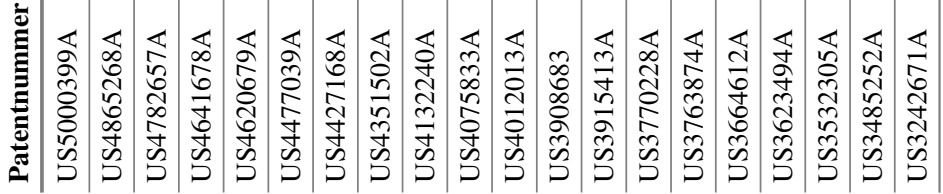




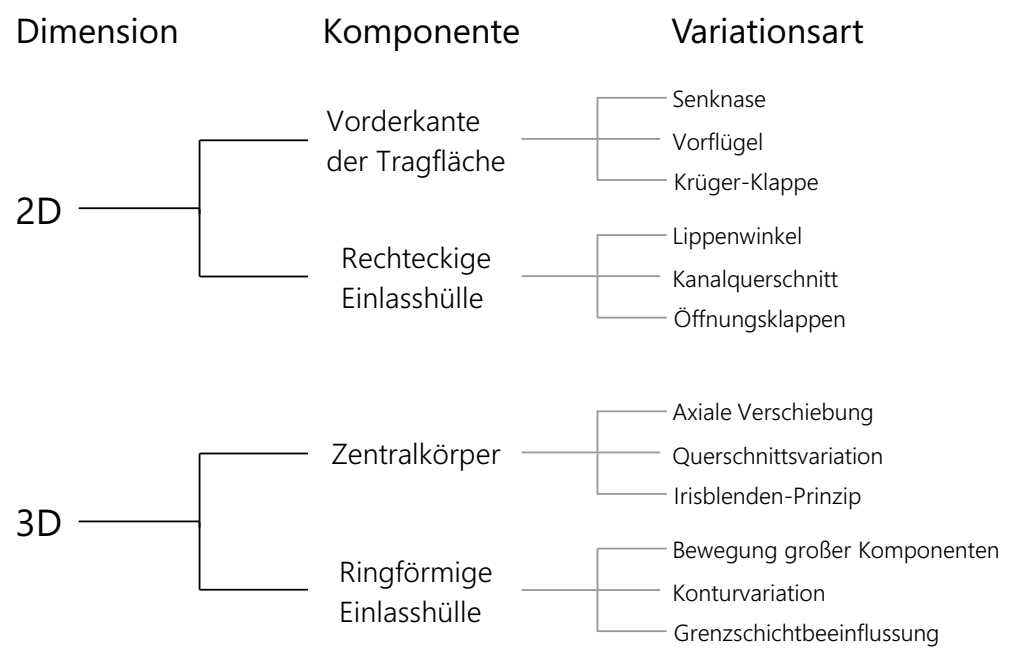

Abbildung 2.24 Kategorien variabler Geometrien

\section{Variable Tragflächenvorderkanten}

Tragflächenprofile stellen Hochauftriebssysteme dar, bei denen die Wölbung und die Profilfläche maximiert werden, während die Ablöseneigung minimiert wird [77, S. 186]. Dabei existieren spaltlose Umsetzungen mit geschlossener Kontur und Umsetzungen mit Spalt [77, S. 186]. Insbesondere im Bereich der Vorderkante liegt der Schwerpunkt auf der Vermeidung von Strömungsablösungen [77, S. 186]. Dafür wird versucht, eine aerodynamisch glatte Kontur zu erzeugen und die Saugspitze an der Profilnase zu verringern [77, S. 187]. Die zahlreichen Lösungsansätze für die Variation der Vorderkante der Tragfläche werden beispielsweise von Niu [220, S. 317-335] zusammengefasst. Diese können in drei Haupttypen unterteilt werden, die in Abbildung 2.25 dargestellt sind:

- das Absenken der Profilnase (Droop Nose) [77, S. 187], [220, S. 333],

- vorgelagerte Strömungsprofile, sogenannte Vorflügel [77, S. 187-189], [220, S. 326], [165] und

- die Krüger-Klappe [77, S. 188], [220, S. 330-332].

Zudem existieren Kombinationen von Droop Nose und Krüger-Klappe [208]. 
Senknase

Eingefahren

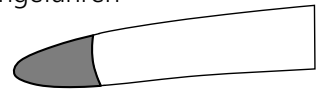

Ausgefahren

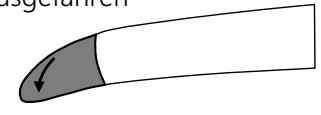

Vorflügel


Krüger-Klappe
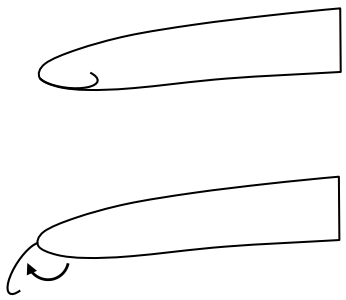

Abbildung 2.25 Variable Hochauftriebssysteme an Tragflächenprofilen

Während Konzepte für variable Vorflügel und Krüger-Klappen aufgrund ihrer Bauweise viel Lärm erzeugen, könnten abgewandelte Droop Nose-Konzepte [150], [151], [175], [179], [209] auch im Bereich der Einlasslippe Anwendung finden. Insbesondere die Übertragung der Verformung der Profilgeometrie von der annähernd ebenen Tragfläche in den dreidimensionalen, ringförmigen Raum des Pitot-Einlasses stellt hierbei eine große Herausforderung dar. Aktuelle Untersuchungen [221], [222], [223], [224] bezüglich Droop Nose-Umsetzungen mit Hilfe intelligenter Werkstoffe (Smart Materials) könnten diese Übertragung unterstützen.

\section{Variable Hülle rechteckiger Einlässe}

Wie in Abbildung 2.26 dargestellt, kann die Gondelgeometrie rechteckiger Einlässe variiert werden durch:

- Verstellung der Lippenwinkel und -form,

- Querschnittsänderungen des primären Strömungskanals und

- Öffnungsklappen im primären Strömungskanal [70, S. 638].

Die Variation des Lippenwinkels und der Lippenkontur [192], [211] ist vergleichbar mit den Lösungsansätzen für variable Tragflächenvorderkanten, insbesondere mit der Droop Nose. Die Lippenvariation ermöglicht eine Anpassung an die vorherrschende Fangstromröhre sowie die Anströmrichtung und ermöglicht das Einstellen gewünschter Stoßkonfigurationen [9]. Beispielsweise werden bei den Flugzeugen F-15 und Eurofighter variable metallische Lippen eingesetzt [9]. Bei der Hawker P1127 wurden aufblasbare Einlasslippen aus Gummi verwendet, die 
aufgrund der eingeschränkten Lebensdauer später durch metallische Konstruktionen ersetzt wurden [9]. Intelligente Werkstoffe bieten auch hier Potenziale, die beispielsweise im Rahmen des SAMPSON-Projekts (Smart Aircraft and Marine Project System Demonstration, Systemdemonstration intelligenter Flugzeug- und Marineprojekte) [225], [226], [227], [228], [229] untersucht wurden.

\section{Lippenwinkel Kanalquerschnitt Öffnungsklappen}
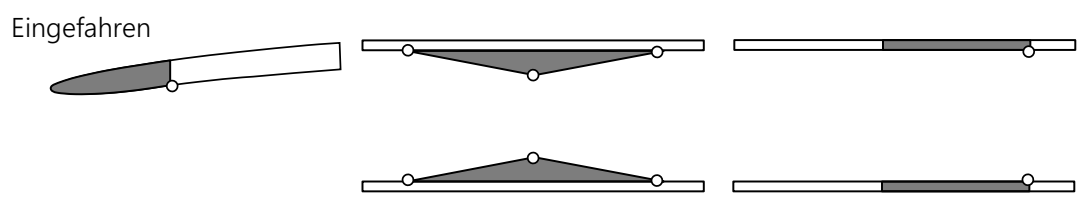

Ausgefahren
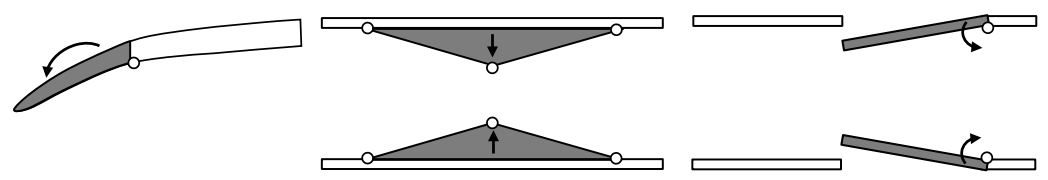

Abbildung 2.26 Variable Konturen rechteckiger Überschall-Einlässe

Durch die Variation des Kanalquerschnitts [168], [197], [205] können vor allem der Triebwerksmassenstrom, sowie die Stärke und die Lage der Verdichtungsstöße gesteuert werden, was die Problematik des Startens von ÜberschallEinlässen abschwächt [10, S. 993-994], [47, S. 349]. Häufig wird die Variation des Kanalquerschnitts mit Öffnungsklappen zur Grenzschichtabscheidung oder Lufteinleitung [193], [200], [212] kombiniert. Diese Nebenstromklappen fanden auch bei Pitot-Einlässen Anwendung, bringen jedoch den Nachteil großer Lärmerzeugung mit sich [9].

\section{Variable Zentralkörper des Einlasses}

Die Variation des konischen Zentralkörpers wird vorrangig bei Einlässen mit gemischter Verdichtung für den Überschallflug eingesetzt, um die erforderlichen Stoßkonfigurationen umzusetzen, vgl. Abschnitt 2.1.3. Dabei kann der Zentralkörper axial verschiebbar sein [189], [201] oder einen variierbaren Querschnitt [201] aufweisen [70, S. 638]. Zudem sind häufig Abluftkanäle zur Grenzschichtabscheidung in den verstellbaren Zentralkörper integriert [9]. 
Eine weitere Möglichkeit der Querschnittsvariation besteht in der Nutzung des Irisblenden-Prinzips. Bei diesem wird, ähnlich einer Kamerablende, der Öffnungsquerschnitt variiert, vgl. Abbildung 2.27 rechts. Anwendung findet dieser Lösungsansatz bei der Sukhoi Su-29 [230].

\section{Axiale Verschiebung Querschnittsvariation Irisblenden-Prinzip}
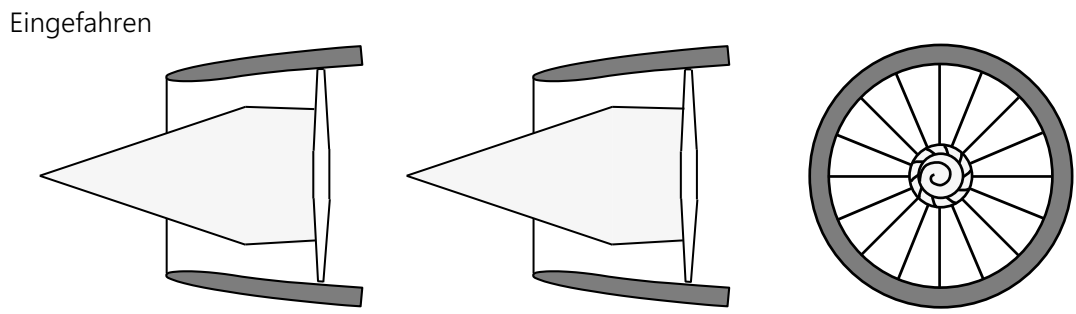

Ausgefahren
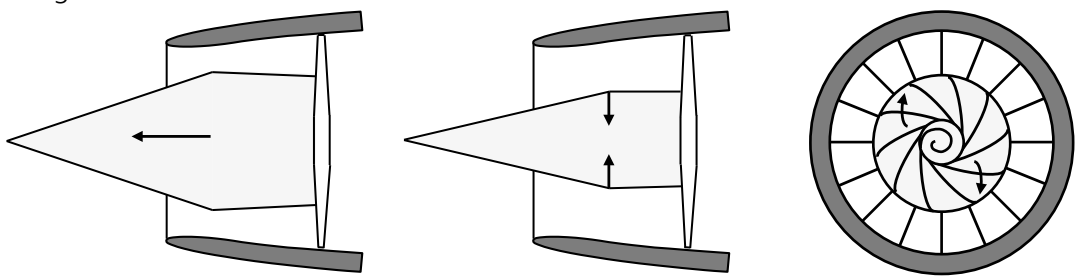

Abbildung 2.27 Variable Zentralkörper

\section{Variable ringförmige Einlässe}

Für die Umsetzung variabler Pitot-Einlasshüllen gibt es drei grundlegende Lösungsansätze, vgl. Abbildung 2.24 unten. Der erste dieser Ansätze ist das Variieren des Einlasses durch Verschieben großer Komponenten. Dabei werden große Bestandteile des Einlasses gekippt, gedreht oder ausgefahren.

Für das Kippen großer Bereiche des Einlasses existieren Varianten, die den gesamten Einlass [163], [217] oder nur einen großen Sektor des Einlasses [217] um eine Achse neigen, vgl. Abbildung 2.28. Mit diesen Varianten kann beispielsweise auf unterschiedliche Anströmwinkel reagiert werden oder der Fanlärm vom Boden abgeschottet werden.

Das Rotieren großer Komponenten beschreibt einen weiteren Lösungsansatz. Hierbei kann der gesamte Einlassring oder seine Lippe um die Triebwerksachse 


\section{Kippen}

Nominalposition

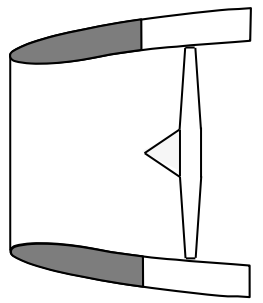

Gesamter Einlassring

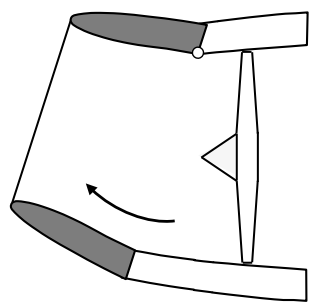

Sektor des Einlasses

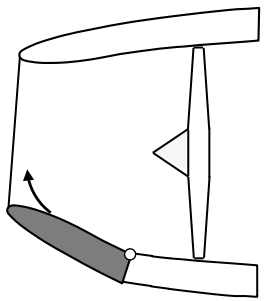

Abbildung 2.28 Einlassvariation durch Kippen großer Bereiche

[164], [216], vgl. Abbildung 2.29, oder um eine dazu versetzte Achse [191] gedreht werden. Dieser Lösungsansatz ist insbesondere für Triebwerke zweckmäßig, deren Einlass halbkreisförmig ausgeführt und nah am Flugzeugrumpf montiert ist. Somit kann für die jeweilige Flugphase die besser geeignete Geometrie eingestellt werden, während die ungünstigere Geometrie im Rumpf verstaut ist.

Weiterhin existiert ein Ansatz [194], bei dem der Einlass sowohl gedreht als auch gekippt werden kann.

Das Ausfahren großer ringförmiger Einlasskomponenten kann durch Verwendung des Teleskop-Prinzips [149], [184], durch axiales Verfahren der Einlasslippe [186], [187] oder durch axiales Herausfahren von Strömungsprofilen aus der Lippe [145], [185] erfolgen, vgl. Abbildung 2.30. Unter dem Teleskop-Prinzip ist zu verstehen, dass ein Teil des Einlasses im Nominalzustand innerhalb der Einlasshülle verstaut ist und bei Bedarf ausgefahren werden kann, um einen Teil der umströmten Kontur zu erzeugen. Bei Verwendung dieser Bauart ohne Segmentierung des Einlasses über den Umfang erfolgt eine reine Längenvariation des Einlasses, die der erhöhten Masse des Systems gegenübersteht. Die Ansätze der verfahrbaren Einlasslippe und der verfahrbaren Profile sind funktionell vergleichbar mit dem Prinzip der Öffnungsklappen im Nebenstromkanal, vgl. Abbildung 2.14. Ziel ist es hierbei, den einfließenden Luftmassenstrom zu maximieren, während Strömungsablösungen vermieden werden. Eine große Herausforderung stellt dabei der Lärm dar, der bei der Umströmung der ausgefahrenen Komponenten entsteht.

Eine Sonderform stellen verschiebbare Ringe im Einlass [98] dar, welche der Strömungsgleichrichtung dienen sollen und gegebenenfalls als Lärmdämmringe 
Abbildung 2.29

Einlassvariation durch

Rotation um die

Triebwerksachse
Rotation um die Triebwerksachse

Zustand 1


Zustand 2
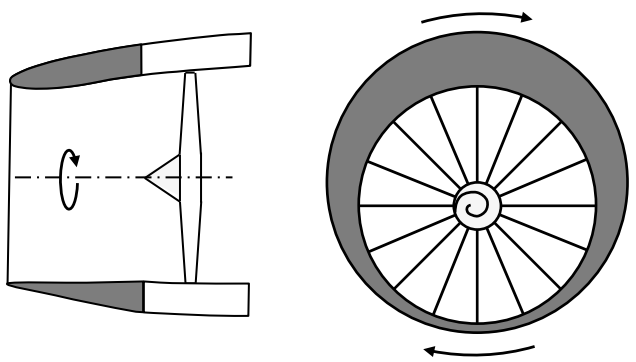

fungieren können, vgl. Abbildung 2.12. Der Strömungseinfluss dieses Ansatzes ist $\mathrm{zu}$ untersuchen.

Die Lösungsansätze durch Verschieben großer Komponenten zeichnen sich überwiegend durch eine einfache Kinematik aus. Der Nachteil dabei ist jedoch, dass die Geometrievariation sehr stark eingeschränkt ist und bei den meisten dieser Konzepte die Funktionalität zu hinterfragen ist. Für die Verschiebung sehr großer und auch schwerer Komponenten sind ebenso große Stellkräfte aufzubringen und die Komponenten des Stellsystem dementsprechend zu dimensionieren. Auch ist der Grad der Detaillierung der meisten dieser Konzepte zu gering, um deren Umsetzbarkeit abschätzen zu können.

Ein größeres aerodynamisches Potenzial weist die zweite grundlegende Herangehensweise auf. Diese besteht in der geometrischen Konturvariation. Hierbei existieren einerseits Ansätze, bei denen gewünschte Öffnungen und Spalte in der resultierenden Kontur entstehen. Anderseits gibt es Ansätze, mit denen annähernd spaltfreie, geschlossene Konturen erzeugt werden können. Die erstgenannten Ansätze verfügen zumeist über eine einfachere Kinematik, erzeugen jedoch aufgrund der entstehenden Verwirbelungen an den Spalten und den Öffnungen viel Lärm. 
Teleskop-Prinzip

Eingefahren

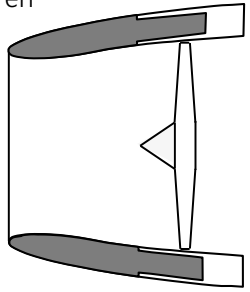

Ausgefahren

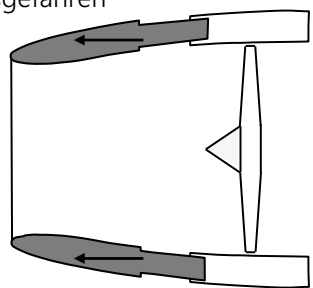

Verfahrbare Lippe



Verfahrbare Profile
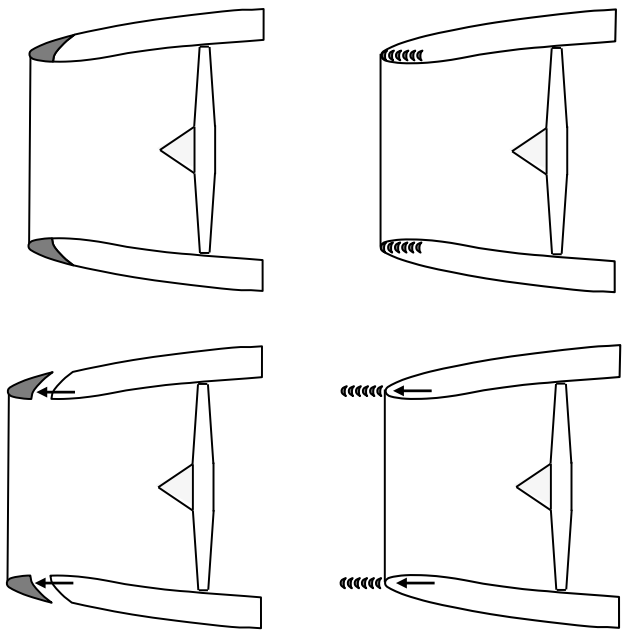

Abbildung 2.30 Einlassvariation durch Ausfahren großer Komponenten

Die Konturvariation erfordert insbesondere radiale Bewegungen bzw. Verformungen von Komponenten. Aufgrund des ringförmigen Aufbaus von PitotEinlässen, können bei radialen Variationen Spalte über den Umfang entstehen oder Bauteilkollisionen auftreten. Um die Entstehung von Spalten und das Auftreten von Bauteilkollisionen zu umgehen, ist bei Verwendung starrer Komponenten eine Segmentierung der Kontur über den Umfang, einschließlich einer Abdichtung der Spalte zwischen den Segmenten, erforderlich. Ansätze für die Abdichtung zwischen den Umfangssegmenten reichen von der Akzeptanz eines Spalts [218] über starre Einfassungen zwischen beweglichen Segmenten [31], [214] und Überlappungen benachbarter Segmente [158] bis hin zur Nutzung von elastischen Materialien zwischen den Segmenten [30].

Beispiele für die Ansätze mit gewünschter Spalterzeugung sind:

- radial verfahrbare Strömungsprofile,

- ausfahrbare Umlenkklappen sowie

- ausfahrbare Öffnungsklappen, vgl. Abbildung 2.31. 
Radiale Profile

Eingefahren

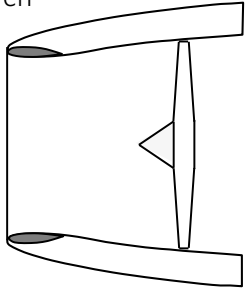

Ausgefahren



Umlenkklappen
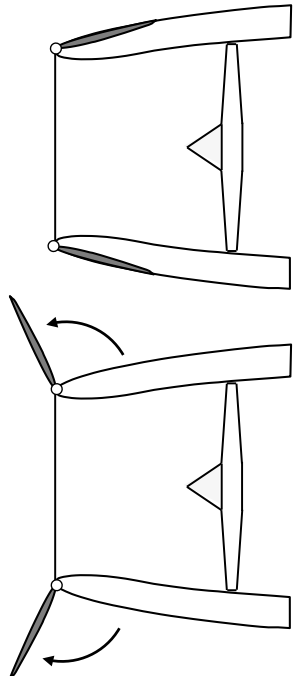

Öffnungsklappen
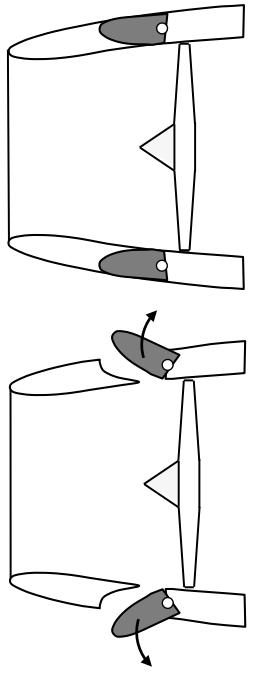

Abbildung 2.31 Konturvariation durch Profile und Klappen

Segmentierte Strömungsprofile können sowohl radial nach innen [166], [172] als auch nach außen [161], [171], [172] verfahren werden. Weiterhin ist eine Kombination mit einer axialen Bewegung [187] möglich. Wie bei den zuvor beschriebenen Lösungsansätzen mit verfahrbaren Profilen besteht auch bei diesen Ansätzen das Ziel darin, den einfließenden Luftmassenstrom zu maximieren und Strömungsablösungen zu minimieren.

Umlenkklappen können auf der Außenseite des Einlasses [144], [213] verwendet werden, um eine Geometrie zu erzeugen, die einem Glockeneinlass ähnelt [10, S. 178-179]. Sie können aber auch an der Innenseite angebracht werden [196] oder vorgelagert sein [202], um beispielsweise den Triebwerkseintrittsmassenstrom zu regulieren.

Öffnungsklappen in der Einlasshülle können genutzt werden, um den effektiven Eintrittsquerschnitt des Einlasses durch Einleiten von Luft [101], [199], [210], [215] zu vergrößern oder durch Ausleiten von Luft [202], [204], [206], [207] zu verkleinern und dabei die Grenzschicht abzuscheiden. Der Unterschied zwischen Öffnungsklappen für ringförmige Anwendungen im Vergleich zu Öffnungsklappen für rechteckige Einlässe besteht darin, dass die Klappen nur einen relativ 
kleinen Kreissektor umfassen können. Andernfalls würden die Spaltverluste zwischen den ausfahrenden Klappen und der gewölbten starren Ringstruktur stark zunehmen.

Lösungsansätze, bei denen eine geschlossene Kontur erzeugt wird, können auf den Prinzipen der Verschiebung starrer Kontursegmente oder der elastischen Verformung des Oberflächenmaterials beruhen. Mit beiden Lösungsansätzen ist es grundlegend möglich, alle geometrischen Parameter des Einlasses zu variieren.

Für das Verschieben starrer Kontursegmente existieren Ansätze zum Verstellen der Lippengeometrie [30], [31], [214], der Diffusorgeometrie [31], [158] sowie der Außenkontur [30]. Ein Ansatz, der alle drei Bestandteile der Geometrie variiert, ist darunter nicht zu finden. Für Ansätze, die die Lippengeometrie variieren, ist eine erhöhte Schadenswahrscheinlichkeit im Fall eines Vogelschlags zu berücksichtigen. Zwei der genannten Ansätze für die Lippenvariation verwenden jedoch eine segmentierte Lippe [31], [214], die im Vogelschlagfall besonders anfällig ist. Der andere Ansatz nutzt einen über den Umfang geschlossenen Ring als Vorderkante der Einlasslippe [30], vgl. Abbildung 2.32. Allerdings wird dieser Ring zur Variation der segmentierten Außenkontur verschoben, sodass während des Stellvorgangs ein großer, sicherheitskritischer Spalt [30, S. 4] im Bereich der Vorderkante entsteht. Für das Realisieren von Querschnittsvariationen erfordert das Verschieben starrer Kontursegmente stets eine Segmentierung über den Umfang der Außenkontur. Dadurch wird einerseits die Komplexität der Konstruktion erhöht. Andererseits entstehen dadurch geringe Abweichungen von einer idealen Kreisgeometrie.

Bei der elastischen Verformung des Oberflächenmaterials existieren sowohl segmentierte [160], [198] als auch über den Einlassumfang geschlossene [147], [153], [155], [156], [176], [183], [188] Lösungsansätze. Die segmentierten Ansätze sind vergleichbar mit den zuvor beschriebenen Ansätzen für das Verschieben starrer Kontursegmente. Sie erzeugen in axialer Richtung eine vergleichsweise glattere Kontur, unterliegen allerdings aufgrund der häufigen elastischen Verformung starkem Verschleiß und können nur einen verhältnismäßig kleinen Verformungsumfang bieten.

Über den Umfang geschlossene Lösungsansätze ermöglichen die aerodynamisch beste Geometrie, indem sie Abweichungen von der Idealgeometrie vermeiden. Jedoch müssen sie dafür die gewünschten unterschiedlichen Materialdehnungen in axialer und in Umfangsrichtung ermöglichen. Hierbei könnten intelligente Werkstoffe [188] oder mit Druckluft verformbare Zellen [147] eingesetzt werden. Das im Rahmen des MorphElle-Projekts entwickelte Konzept [23], [24], [25], [26] verwendet ebenfalls pneumatisch verformbare Zellen. Bei diesem 


\section{Konturvariation mit starren Segmenten}

Ausgefahren

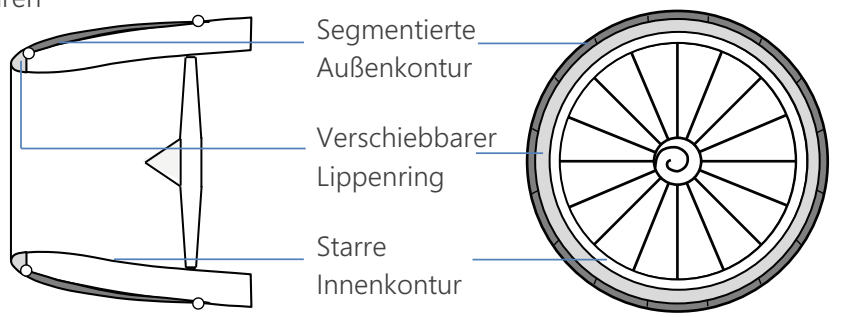

Eingefahren
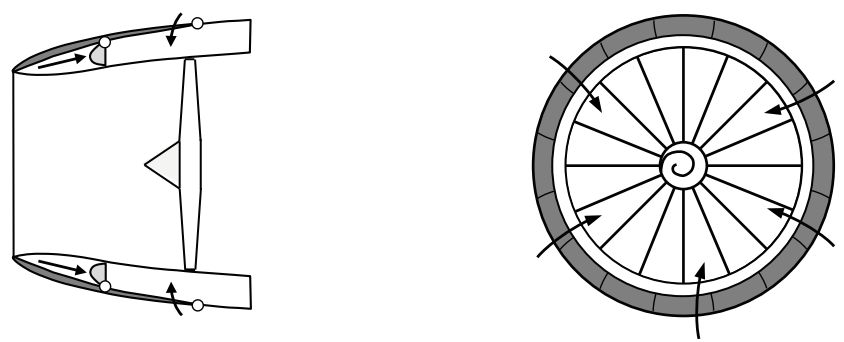

Abbildung 2.32 Konturvariation durch Verschieben starrer Segmente

Typ ist insbesondere zu beachten, dass druckbeaufschlagte Zellen versagensanfällig bei Fremdkörpereinschlägen und Vogelschlägen sind sowie starkem Verschleiß durch Erosion unterliegen.

Die dritte grundlegende Herangehensweise für die Umsetzung variabler Einlässe besteht in der Grenzschichtbeeinflussung [231]. Diese ermöglicht die Verwendung schlanker Geometrien mit einem geringen Luftwiderstand durch die Vermeidung von Strömungsablösungen [232]. Lösungsansätze für die Grenzschichtbeeinflussung können in passive und aktive Mechanismen unterteilt werden [77, S. 186-189].

$\mathrm{Zu}$ den passiven Ansätzen zählen beispielsweise die Grenzschichtabscheidung und die vorgestellten Einsatzmöglichkeiten von Strömungsprofilen [233]. Ansätze der Grenzschichtabscheidung [202], [204], [206], [207] leiten die Strömung im wandnahen Bereich durch einen größeren Strömungskanal nach außen [233], vgl. Abbildung 2.26 rechts und Abbildung 2.30 zentral. Die vorgestellten Einsatzmöglichkeiten von Strömungsprofilen [102], [145], [161], [166], [171], [172], [187] verhindern die Entstehung von Strömungsablösungen, ähnlich wie Vorflügel [77, S. 186-189], vgl. Abbildung 2.30 rechts und Abbildung 2.31 links. 
Einen Sonderfall der Strömungsprofile stellen Wirbelgeneratoren im Strömungskanal dar [11, S. 69-71]. Diese erhöhen die Turbulenz der Strömung und sollen dadurch Strömungsablösungen vermeiden. Wirbelgeneratoren können starr [181] und ausfahrbar [173] ausgeführt werden.

Zur aktiven Grenzschichtbeeinflussung zählen das Absaugen der Strömungsgrenzschicht durch kleine Absaugschlitze [162], [169], das Einblasen in die Grenzschicht [159], [177] und Kombinationen [170] dieser Ausführungen [77, S. 189-190], [234, S. 121], vgl. Abbildung 2.33. Auch das Konzept von Kondor et al. [27], [28], [29] ist zum Einblasen in die Grenzschicht zu zählen.

Grenzschichtabsaugung

Starre Einlasskontur



Detailansicht Z

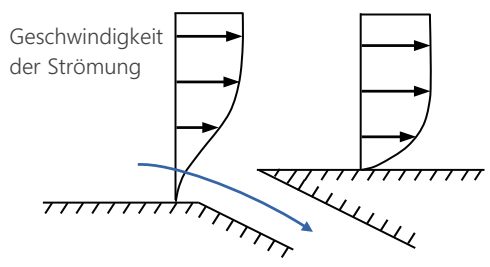

Absaugschlitz

\section{Grenzschichteinblasung}

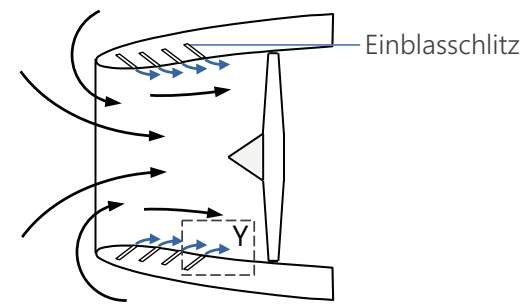

Detailansicht $Y$

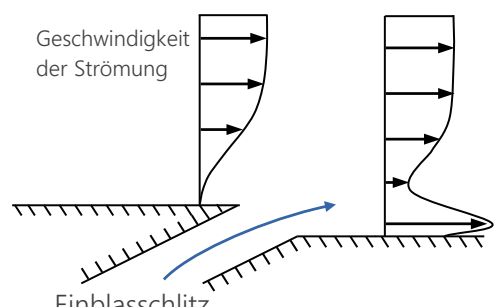

Einblasschlitz

Abbildung 2.33 Konturvariation durch Grenzschichtbeeinflussung

Durch das Einblasen bzw. das Absaugen wird die Strömungsgrenzschicht im wandnahen Bereich stabilisiert und Strömungsablösungen werden vermieden [77, S. 190]. Eine Herausforderung dieser Ansätze stellt der Schutz der jeweiligen Schlitze vor Verschmutzung bzw. Verstopfung dar. Zudem ist ein Regelsystem erforderlich, das den zu- bzw. abzuführenden Luftmassenstrom steuert. Letztlich müssen für einen möglichen Ausfall des Grenzschichtbeeinflussungssystems 
Vorkehrungen getroffen werden, durch die sichergestellt werden kann, dass der Einlass weiterhin seine Funktion erfüllt.

Zusammenfassend ist festzuhalten, dass die meisten bisher aufgezeigten Lösungsansätze Potenzial bezüglich einer Verbesserung der Einlassumströmung bieten. Jedoch weisen dabei alle Ansätze individuelle Schwachpunkte bezüglich der Erfüllung von Anforderungen, wie Strömungseigenschaften, Lärmemissionen, Zuverlässigkeit oder Sicherheit, auf. Diese Schwachpunkte können auf verschiedene Ursachen zurückzuführen sein:

- dem niedrigen Grad der Detaillierung einiger Lösungsansätze,

- einem ungeeigneten konstruktionsmethodischen Ansatz sowie

- den potenziell erforderlichen Technologien.

\subsubsection{Potenzielle Technologien variabler Pitot-Einlässe}

In Abhängigkeit des gewählten Lösungsansatzes erfordern variable Einlässe zusätzliche oder neuartige Technologien. Zusätzliche Technologien können die Ausfallwahrscheinlichkeit der Einlassfunktion erhöhen. Bezüglich neuartiger Technologien existieren nur geringe bis keine Erfahrungswerte, was durch kostenintensive Erprobungen ausgeglichen werden muss. Beides wird in der Luftfahrt nach Möglichkeit vermieden.

Innerhalb eines variablen Einlasses stellt beispielsweise eine Aktorik zum Verschieben von Segmenten eine zusätzlich erforderliche Technologie dar. Eine neuartige Technologie stellt insbesondere die Verwendung formvariabler Werkstoffe für die elastische Oberflächenverformung dar.

\section{Aktorik}

Die Aktorik bildet gemeinsam mit der Sensorik und der Informationsverarbeitung die Bestandteile eines mechatronischen Systems [235, S. 1]. Der Begriff Aktor beschreibt eine ansteuerbare Stelleinrichtung in einem technischen System, die Kräfte oder Bewegungen erzeugen kann [235, S. 1]. Hierfür sind ein Energiesteller und ein Energiewandler erforderlich [235, S. 9]. Der Energiesteller erzeugt aus einem Stellsignal geringer elektrischer Leistung und der extern zugeführten Hilfsenergie eine Stellenergie [235, S. 9]. Diese Stellenergie wird im Energiewandler, beispielsweise einem Motor, unter Abgabe von Verlusten in mechanische Energie umgewandelt [235, S. 9]. 
Als Energieformen der Hilfsenergie können Fluidenergie sowie elektrische, chemische und thermische Energie dienen [235, S. 5]. Zudem werden konventionelle und unkonventionelle Aktoren [236] unterschieden. Bei konventionellen Aktoren sind die Wirkprinzipe hinlänglich bekannt, während für unkonventionelle nur geringe Erfahrungswerte existieren [235, S. 5]. Bei konventionellen Aktoren handelt es sich beispielsweise um Elektromotoren, Elektromagnete oder hydraulische Stelleinrichtungen [235, S. 6]. Zu den unkonventionellen Aktoren zählen beispielsweise Piezoaktoren, magnetorheologische Aktoren und Memorymetallaktoren [235, S. 6-7].

Neben Energiesteller und -wandler kann ein Aktor optionale Komponenten umfassen. An den Energiewandler können verlustbehaftete Übertrager von Kräften, beispielsweise Getriebe oder Gewindespindeln, angeschlossen sein [235, S. 10-11]. Zudem kann der Aktor um eine Positionsregelung, bestehend aus Sensorik und Regeleinrichtung, erweitert werden [235, S. 10-11], vgl. Abbildung 2.34. Die Sensorik kann beispielsweise Winkeländerungen der Motorwelle oder eines Energieübertragers messen. Details bezüglich Sensortechnologien können der Fachliteratur [237], [238], [239] entnommen werden.

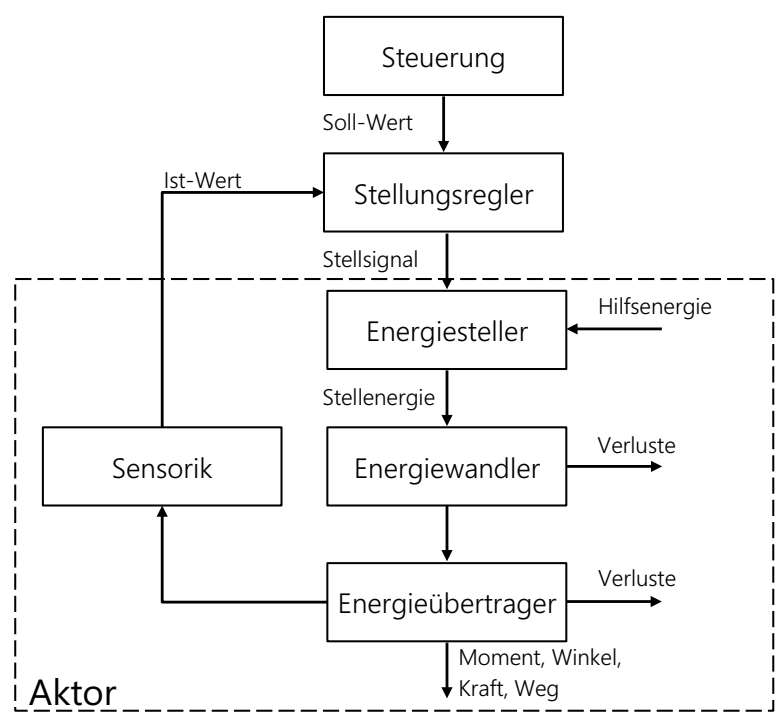

Abbildung 2.34 Aktor mit Positionsregelung und Energieübertrager 
In der Luftfahrt werden vorrangig pneumatisch, hydraulisch oder elektrisch betriebene konventionelle Aktoren verwendet [10, S. 187-188]. Moir et al. [78, S. 18-35], [79, S. 372-379] und Rossow et al. [77, S. 746-748] geben einen ausführlichen Überblick über die einzelnen Bauweisen. Dabei existieren Entwicklungstendenzen in Richtung einer stärkeren Nutzung elektrischer Anbauteile (More Electric Aircraft) bis hin zum ausschließlich elektrischen Flugzeug (All Electric Aircraft) [77, S. 748], [79, S. 377-378].

Elektromechanische Aktoren (EMAs) stellen hierfür eine reinelektrische Lösung dar, die bereits seit vielen Jahren im Bereich von Höhenleitwerken sowie Vorder- und Hinterkanten von Tragflächen Anwendung findet [77, S. 748], [79, S. 378-379]. Als Energiesteller fungiert beim EMA eine Motorsteuerung (Power Drive Electronics) [79, S. 377], [81, S. 100], vgl. Abbildung 2.35. Gespeist wird die Motorsteuerung mit dem Stellsignal aus der Aktorsteuerung (Actuator Control Electronic, ACE) und der Hilfsenergie in Form von Dreiphasenwechselstrom aus dem elektrischen System des Flugzeugs [79, S. 377]. Daraus erzeugt die Motorsteuerung die Stellenergie, die sie an einen als Energiewandler genutzten Elektromotor weiterleitet. Die vom Elektromotor erzeugte mechanische Energie wird über ein Getriebe und einen Gewindetrieb an den gewünschten Ort übertragen und in Form einer axialen Bewegung bzw. Kraft genutzt. Für die Positionsregelung des Aktors ist ein Drehwinkelgeber am Getriebe angebracht [79, S. 377]. Dieser Sensor leitet den gemessenen Ist-Wert des Aktors an die Aktorsteuerung weiter. Dort wird der Ist-Wert mit dem von der Flugzeugsteuerung, beispielsweise dem Fly-by-Wire-System, vorgegebenen Soll-Wert abgeglichen und ein aktualisiertes Stellsignal erzeugt [79, S. 377].

Im Vergleich zu hydraulischen und pneumatischen Lösungen sind EMAs potenziell

- kompakter,

- leichter,

- weisen einen höheren Wirkungsgrad auf,

- verfügen über ein breiteres Leistungsspektrum,

- ermöglichen einen gleichmäßigeren Betrieb,

- erfordern weniger Anbauteile, wie Pumpen und Rohrleitungen, und

- vermeiden das Risiko von Leckagen [240].

Ein Nachteil von EMAs besteht in den erhöhten Anschaffungskosten, die größtenteils durch geringere Lebenswegkosten ausgeglichen werden [240]. Zudem existiert das Risiko des Verklemmens des Aktors [79, S. 379]. 


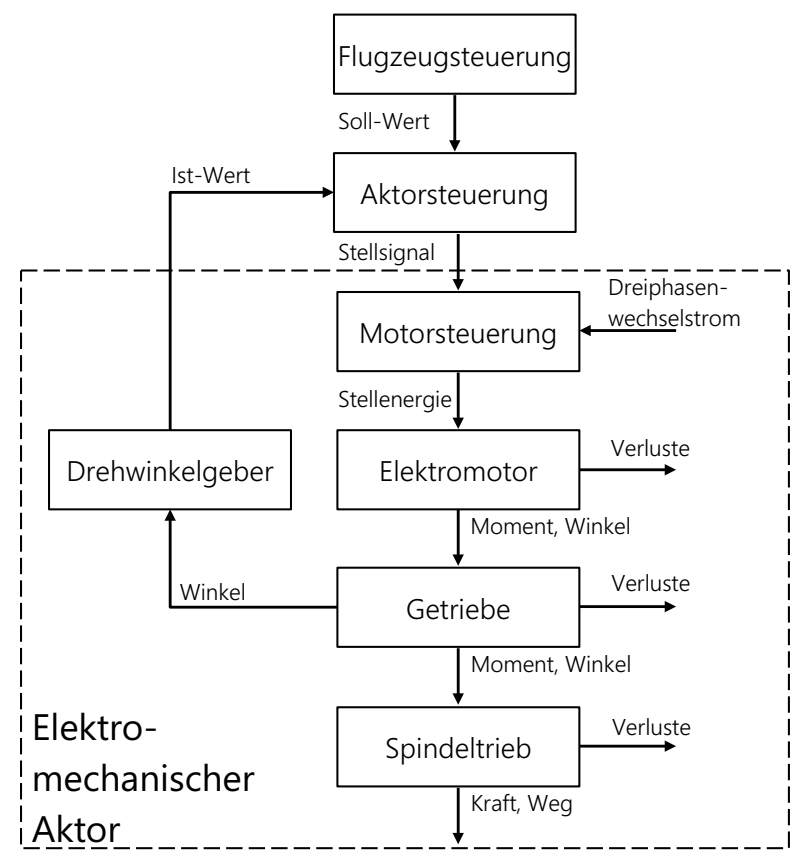

Abbildung 2.35 Elektromechanischer Aktor

Der Ausfall eines Aktors muss in Abhängigkeit der betroffenen Komponenten und der entstehenden Folgen kompensiert werden. Beispielsweise werden beim Airbus A330 die Aktoren der Steuerflächen redundant ausgeführt [77, S. 748]. Dabei wird zumeist nur ein Aktor pro Steuerfläche aktiv eingesetzt, während die verbleibenden in einem Ruhemodus verweilen, bis deren Einsatz erforderlich wird. Auch die Energieversorgung findet hierbei unabhängig voneinander statt [77, S. 749]. Bei den Störklappen dieses Flugzeugs wird auf diese Redundanz verzichtet [77, S. 748-749].

Die fehlerhafte Ansteuerung von Aktoren bei Schubumkehrsystemen wird vermieden, indem vor einer Freigabe der Aktorverstellung mehrere Statusabfragen durchgeführt werden [76, S. 192]. Hierzu zählen der Bodenabstand, die Schubhebelstellung und die Verfügbarkeit von Energie [76, S. 192]. Zudem werden beim Schubumkehrer verschiedene unabhängige Verschlusssysteme eingesetzt, um ein unbeabsichtigtes Ausfahren des Aktors zu verhindern [54, S. 92-94], [67, S. 160]. 


\section{Formvariable Strukturen}

Traditionell eingesetzte metallische Werkstoffe unterstützen eine elastische Konturvariation nur in einem verhältnismäßig geringen Umfang bevor plastische Verformung einsetzt. Formvariable (Morphing) Strukturen ermöglichen eine gröBere Verformung. Sie werden auch als adaptive, aktive oder smarte Strukturen bezeichnet [77, S. 429]. Diese Strukturen sind beispielsweise über aktuierte Elastomere, elastisch verformbare Verbundwerkstoffe oder intelligente Werkstoffe (Smart Materials) realisierbar [77, S. 429].

Elastomere finden in der Luftfahrt bereits Anwendung, beispielsweise bei Abdichtungen im Bereich der Tragflächen. In den letzten Jahren wurden zudem elastisch verformbare Verbundstrukturen für die Anwendung in intelligenten Droop Nose-Tragflächenkonzepten, vgl. Abschnitt 2.4.2, untersucht [221], [222], [241], [242], [243]. Aber auch in anderen Bereichen des Flugzeuges, wie beispielsweise beim Leitwerk, wird die Anwendung dieser Strukturen in Betracht gezogen [223].

Intelligente Werkstoffe integrieren die Funktionen eines Aktors oder Sensors [244, S. 1]. Sie können externe Reize zur Änderung ihrer Eigenschaften nutzen. Beispiele dieser externen Reize sind Änderungen der Temperatur, des Magnetfeldes, des elektrischen Potenzials und der Lichteinstrahlung [244, S. 2]. Entsprechend der Reaktion auf den externen Reiz, werden unter anderem folgende Typen intelligenter Materialien unterschieden:

- piezoelektrische, elektrostriktive oder dielektrische Materialien, deren interne Spannungen und Geometrien sich unter dem Einfluss elektrischer Spannungen und Felder verändern,

- magnetorheologische und elektrorheologische Fluide, die sich durch magnetische bzw. elektrische Felder verfestigen können,

- Formgedächtnislegierungen (Shape Memory Alloys, SMAs) und Formgedächtnispolymere (Shape Memory Polymers SMPs), deren Geometrien sich in Abhängigkeit der Temperatur ändern können [77, S. 433], [245], [246], [247], [248], [249, S. 207-208].

Diese Effekte werden auch in unkonventionellen Aktoren genutzt. Diesbezüglich stellt Janocha [236] umfassende Informationen bereit.

Insbesondere Formgedächtnislegierungen werden in den Bereichen Medizin, Robotik, Automobilindustrie sowie Luft- und Raumfahrt umfänglich untersucht [244], [250]. Dadurch wird die Gesamtzahl von Patenten für die Anwendung von Formgedächtnislegierungen inzwischen auf über 30.000 geschätzt [250]. Darunter sind auch zahlreiche Patente [146], [152], [167] mit Relevanz für die 
Triebwerksgondel zu finden. Im Rahmen des SAMPSON-Projekts [225], [226], [227], [228], [229] wurden zudem Kombinationen von Formgedächtnislegierungen mit Elastomeren im Bereich der Einlasslippe rechteckiger Triebwerkseinlässe untersucht.

Während Tragflächen und die Wände rechteckiger Einlässe annähernd eben sind, sind Pitot-Einlässe ringförmig. Daher muss die formvariable Struktur auch in Umfangsrichtung anpassungsfähig sein. Daraus ergeben sich anspruchsvollere mechanische Anforderungen an die Struktur. Ein Lösungsansatz hierfür wurde im Rahmen des MorphElle-Projekts erarbeitet. Hierbei wird eine elastisch verformbare Haut erzeugt, indem eine Silikonmatrix mit Metalldrähten verstärkt wird [26]. Die Verformung der Haut wird durch Druckveränderungen in dahinterliegenden Schläuchen gesteuert [26]. Vor einer Anwendung in der Luftfahrt sind die Zuverlässigkeit und die Lebensdauer, insbesondere die Erosionsbeständigkeit, dieses Lösungsansatzes zu untersuchen.

Open Access Dieses Kapitel wird unter der Creative Commons Namensnennung 4.0 International Lizenz (http://creativecommons.org/licenses/by/4.0/deed.de) veröffentlicht, welche die Nutzung, Vervielfältigung, Bearbeitung, Verbreitung und Wiedergabe in jeglichem Medium und Format erlaubt, sofern Sie den/die ursprünglichen Autor(en) und die Quelle ordnungsgemäß nennen, einen Link zur Creative Commons Lizenz beifügen und angeben, ob Änderungen vorgenommen wurden.

Die in diesem Kapitel enthaltenen Bilder und sonstiges Drittmaterial unterliegen ebenfalls der genannten Creative Commons Lizenz, sofern sich aus der Abbildungslegende nichts anderes ergibt. Sofern das betreffende Material nicht unter der genannten Creative Commons Lizenz steht und die betreffende Handlung nicht nach gesetzlichen Vorschriften erlaubt ist, ist für die oben aufgeführten Weiterverwendungen des Materials die Einwilligung des jeweiligen Rechteinhabers einzuholen. 